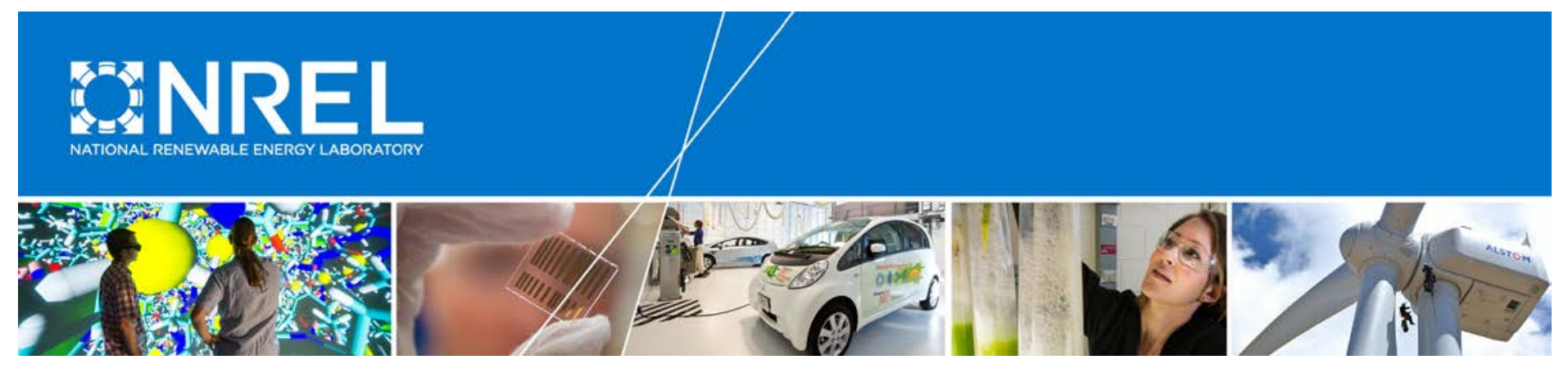

\title{
The Relative Economic Merits of Storage and Combustion Turbines for Meeting Peak Capacity Requirements under Increased Penetration of Solar Photovoltaics
}

Paul Denholm, Victor Diakov, and Robert Margolis National Renewable Energy Laboratory

NREL is a national laboratory of the U.S. Department of Energy Office of Energy Efficiency \& Renewable Energy Operated by the Alliance for Sustainable Energy, LLC

This report is available at no cost from the National Renewable Energy Laboratory (NREL) at www.nrel.gov/publications.

Technical Report

NREL/TP-6A20-64841

September 2015 


\section{The Relative Economic Merits of Storage and Combustion Turbines for Meeting Peak Capacity Requirements under Increased Penetration of Solar Photovoltaics}

\author{
Paul Denholm, Victor Diakov, \\ and Robert Margolis
}

Prepared under Task Nos. SS13.1040 and TM13.1502
NREL is a national laboratory of the U.S. Department of Energy Office of Energy Efficiency \& Renewable Energy Operated by the Alliance for Sustainable Energy, LLC

This report is available at no cost from the National Renewable Energy Laboratory (NREL) at www.nrel.gov/publications.

\section{Technical Report}

NREL/TP-6A20-64841

September 2015

Contract No. DE-AC36-08GO28308
National Renewable Energy Laboratory 15013 Denver West Parkway

Golden, CO 80401

303-275-3000 • www.nrel.gov 


\title{
NOTICE
}

This report was prepared as an account of work sponsored by an agency of the United States government. Neither the United States government nor any agency thereof, nor any of their employees, makes any warranty, express or implied, or assumes any legal liability or responsibility for the accuracy, completeness, or usefulness of any information, apparatus, product, or process disclosed, or represents that its use would not infringe privately owned rights. Reference herein to any specific commercial product, process, or service by trade name, trademark, manufacturer, or otherwise does not necessarily constitute or imply its endorsement, recommendation, or favoring by the United States government or any agency thereof. The views and opinions of authors expressed herein do not necessarily state or reflect those of the United States government or any agency thereof.

This report is available at no cost from the National Renewable Energy Laboratory (NREL) at www.nrel.gov/publications.

Available electronically at SciTech Connect http:/www.osti.gov/scitech

Available for a processing fee to U.S. Department of Energy and its contractors, in paper, from:

\author{
U.S. Department of Energy \\ Office of Scientific and Technical Information \\ P.O. Box 62 \\ Oak Ridge, TN 37831-0062 \\ OSTI http://www.osti.gov \\ Phone: 865.576.8401 \\ Fax: 865.576.5728 \\ Email: reports@osti.gov
}

Available for sale to the public, in paper, from:

\author{
U.S. Department of Commerce \\ National Technical Information Service \\ 5301 Shawnee Road \\ Alexandria, VA 22312 \\ NTIS http://www.ntis.gov \\ Phone: 800.553 .6847 or 703.605 .6000 \\ Fax: 703.605.6900 \\ Email: orders@ntis.gov
}




\section{Acknowledgements}

This work was funded by Solar Energy Technologies Office of the Department of Energy Office of Energy Efficiency and Renewable Energy under contract number DE-AC36-08GO28308. For their review and comments, the authors would like to thank Aaron Bloom, Thomas Jenkin, Praveen Kathpal, Kiran Kumaraswamy, Mark Mehos, Mike Meshek, David Mooney, Keith Parks, Ramteen Sioshansi, and Aidan Tuohy. Ali Ehlen assisted with data processing. Any errors or omissions are solely the responsibility of the authors. 


\section{Abstract}

Batteries with several hours of capacity provide an alternative to combustion turbines for meeting peak capacity requirements. Even when compared to state-of-the-art highly flexible combustion turbines, batteries can provide a greater operational value, which is reflected in a lower system-wide production cost. By shifting load and providing operating reserves, batteries can reduce the cost of operating the power system to a traditional electric utility. This added value means that, depending on battery life, batteries can have a higher cost than a combustion turbine of equal capacity and still produce a system with equal or lower overall life-cycle cost. For a utility considering investing in new capacity, the cost premium for batteries is highly sensitive to a variety of factors, including lifetime, natural gas costs, PV penetration, and grid generation mix. In addition, as PV penetration increases, the net electricity demand profile changes, which may reduce the amount of battery energy capacity needed to reliably meet peak demand. 


\section{Table of Contents}

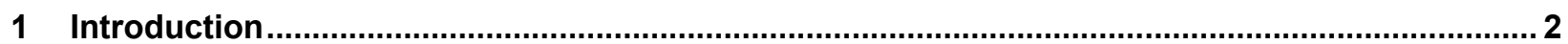

2 Study Framework and Methods ............................................................................................ 3

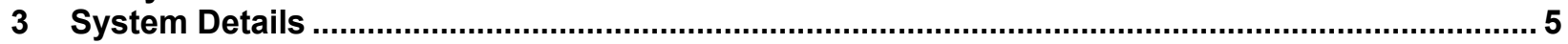

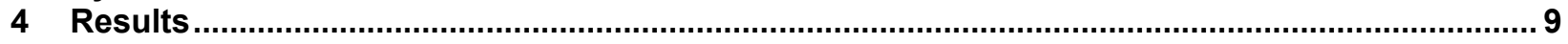

4.1 Differences in Operational Costs ......................................................................... 9

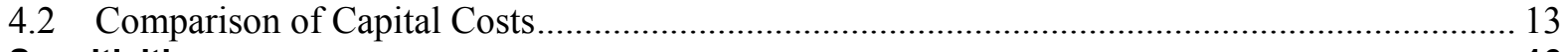

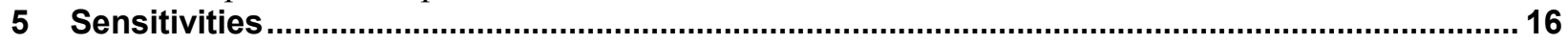

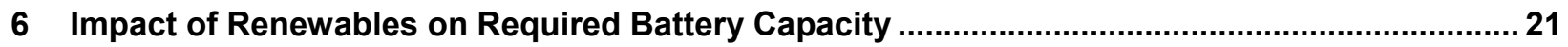

7 Market Challenges................................................................................................................ 26

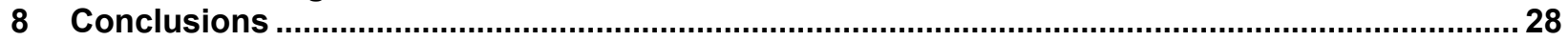

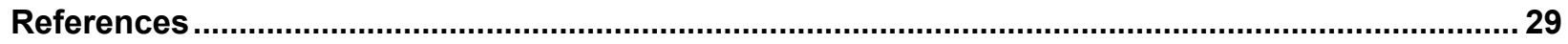

Appendix A. Derivation of the Relationship between Battery Cost and CT Cost........................... 33

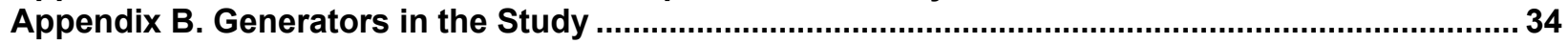




\section{List of Figures}

Figure 1. Battery cost that results in a system cost equivalent to that of a combustion turbine (CT) as function of lifetime for combinations of PV penetration and CT costs................................... 15

Figure 2. Battery cost that results in a system cost equivalent to a $\$ 1,200 / \mathrm{kW} \mathrm{CT}$ as function of lifetime for the $15 \%$ PV penetration sensitivity cases............................................................ 17

Figure 3. Additional cost of a battery $(\$ / \mathrm{kW})$ that results in a system cost equivalent to a $\$ 1,200 / \mathrm{kW}$

$\mathrm{CT}$ as function of lifetime for the $15 \% \mathrm{PV}$ penetration sensitivity cases.

Figure 4. Battery cost that results in a system cost equivalent to a $\$ 1,200 / \mathrm{kW} \mathrm{CT}$ as function of lifetime for the $15 \% \mathrm{PV}$ case where both the CT and battery can provide regulation reserves .. 20

Figure 5. Normal load (no VG) and net load with $20 \%$ wind and $15 \%$ PV

Figure 6. Narrowing of net peak and amount of storage needed to deliver a 500-MW peak demand

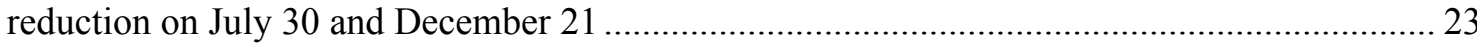

Figure 7. Hours of storage needed to reduce peak demand by $500 \mathrm{MW}$ and 1,000 MW as a function of PV penetration

Figure 8 . Breakeven battery cost $(\$ / \mathrm{kWh})$ in the $15 \%$ PV case where only two hours of the battery is dispatched

\section{Lists of Tables}

Table 1. Generation Capacity of the Test System (MW) ............................................................... 6

Table 2. Operational Parameters of New Generation Capacity ........................................................... 7

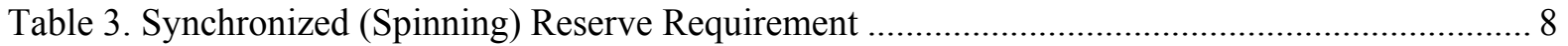

Table 4. Annual Operational Costs of the Test System (M\$) …...................................................... 9

Table 5. Breakdown of Services (GWh or GW-hr) ${ }^{\text {a }}$ Provided by 500-MW 4-Hour Battery ............... 10

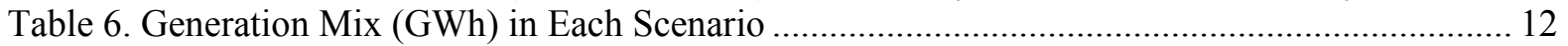

Table 7. Approximate Net "Source" of Charging Energy (percentage from Source) ........................... 12

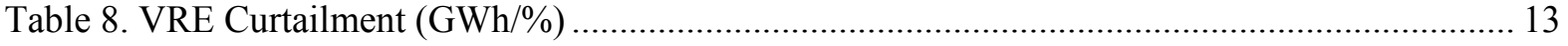

Table 9. Fixed Cost Components of New Generation Capacity ........................................................ 14

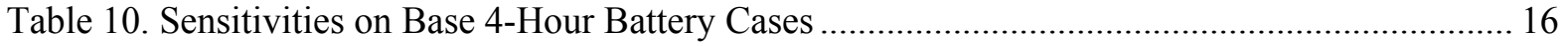

Table 11. Reduction in Annual Operational Costs of Replacing a 500-MW CT with $500 \mathrm{MW}$ of

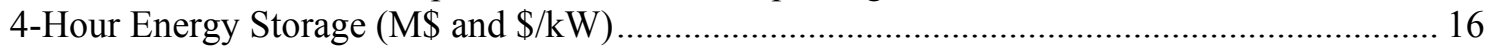

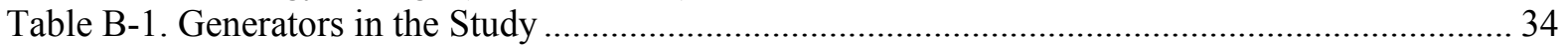




\section{Introduction}

Peak demand in the United States is often met using simple-cycle gas turbines, which can start and ramp quickly. Decreasing costs of energy storage may make these technologies an increasingly competitive means of providing system capacity as well as other energy and ancillary services. An additional consideration is the impact of increased deployment of photovoltaics (PV) on the relative economics of combustion turbines vs. energy storage. At high penetration of $\mathrm{PV}$, mismatches in supply and demand can produce increasing rates of curtailed energy, which could be partially mitigated by deploying energy storage.

In this work, we analyze the economic opportunities for energy storage to provide capacity and energy services at high levels (15\%-20\% of annual energy) of PV penetration. We simulate the annual operating cost of a system where we add either a new CT or a new battery and calculate the operational savings provided by either type of generation. We demonstrate that a battery can reduce the overall cost of operating the power grid compared to a CT when considered from the perspective of a traditional vertically integrated utility. We then evaluate how this annual operational cost savings translates into the required capital cost for a battery to be competitive with combustion turbines for a utility considering investment in new capacity. We find that under many scenarios, storage can cost considerably more than a new CT (measured using the traditional metric of cost per unit of power capacity) and still produce the same life-cycle cost. However, this depends greatly on battery life - batteries with a life of less than 10 years will likely need to have costs similar to CTs, while batteries with a 20 -year life could have a cost approaching twice the cost of CTs and still produce a similar life-cycle system cost. The overall cost of a utility-scale battery is also driven by the hours of needed capacity. We find that under increased penetration of PV, changes in demand patterns could enable batteries with less than four hours of capacity to provide the same level of capacity as a new CT. Finally, we discuss several ongoing challenges for storage to be able to compete in restructured markets, including the need for optimized storage scheduling and appropriate compensation for its reduction in system operating costs. 


\section{Study Framework and Methods}

This analysis considers cases of increasing PV penetration, ${ }^{1}$ especially cases where the capacity value of incremental PV has substantially dropped. In much of the United States, peak demand for electricity occurs in the late afternoon on hot summer days. These days are typically sunny, and there is usually a high level of solar output from PV. The correlation between peak demand and solar output results in a substantial capacity credit for solar generation, meaning the solar PV can be expected to reliably contribute to meeting peak demand (Madaeni et al. 2013). For example, a previous study of solar in Colorado (including the region studied in this analysis) estimated a capacity credit of $27 \%-32 \%$ for PV fixed arrays and $40 \%-47 \%$ for PV with tracking systems (Xcel Energy 2013). Across the United States, studies have found a capacity credit in the range of $30 \%-75 \%$ at low penetration (Mills and Wiser 2012a). A challenge occurs as PV penetration increases and PV shifts the net load peak (or normal peak load minus the contribution from PV and wind) to periods of low solar output (Jorgenson et al. 2014).

Several of the studies cited by Mills and Wiser (2012a) as well as a study by Jorgenson et al. (2014) indicate that at penetrations in the range of $15 \%$ (on an energy basis), the incremental capacity credit of PV can be very low. In these cases, additional PV will continue to offset energy but not capacity. As older generators retire, they would need to be replaced with new capacity. An outstanding challenge involves determining the optimal mix of sources of new capacity in cases of increased PV penetration.

This analysis compares the system costs of two sources of additional capacity in cases where older generators are retired in the presence of increased PV penetration. Specifically, we explore cases where PV reaches $15 \%-20 \%$ penetration on an energy basis and existing generation is retired due to age, carbon constraints, or reduced utilization. We then compare the relative costs and benefits of adding new combustion turbines (CTs) versus energy storage, considering a range of assumptions and sensitivities.

The overall economic performance metric we apply in this analysis is best framed by the following question: how much more (or less) can a battery cost for the two systems (added battery or added CT) to have equivalent total costs? The answer to the question represents the point at which a utility would be indifferent about installing a CT or a battery. Our approach corresponds to a least-cost planning framework, which is typically associated with vertically integrated utilities in regions without restructured markets. Previous estimates of this "breakeven" point for energy storage under historic market conditions are provided by EPRI (2013), Lyons (2014), Cutter et al. (2014), Ricci and Jung (2015), and Akhil et al. (2015).

Performing this comparison requires estimating the impacts on both capital costs and operational costs. Adding generation to a system incurs a cost associated with fixed capacity costs. If two generators provide identical operational benefits, a capital cost comparison is relatively simple and requires only consideration of issues such as project financing and equipment lifetime (i.e., batteries typically have shorter lifetimes than CTs). However because batteries operate in a manner substantially different from CTs, the impact on operational costs of both options must be considered. Adding a new generator to a system will typically provide a benefit associated with a

\footnotetext{
${ }^{1}$ For all cases in this report, PV penetration is defined as the fraction of total annual energy provided by PV.
} 
reduction in operational costs. In the case of the $\mathrm{CT}$, a newer and more efficient generator will reduce the output of older, less efficient peaking capacity. In the case of the battery, it will increase use of lower-cost baseload generation as well as improve system efficiency by providing reserves and reducing power plant cycling and starts. As the penetration of variable generation (VG) increases, energy storage can also reduce wind and solar curtailment and displace fossil generation.

The value of an additional resource can be estimated using historical price data (EPRI 2013, Cutter et al. 2014). However, estimating impacts in a future grid scenario, such as that evaluated here, is typically performed using a production cost model. A production cost model performs chronological simulation of the entire generation fleet over some period (typically one year). ${ }^{2} \mathrm{~A}$ complete comparison of two scenarios requires estimating the operational costs of the system over the life of the installed capacity, which requires numerous assumptions, including assumptions about changes in fuel price and grid mix for each year. These changes would then be simulated over an extended period; for example, if a CT has an expected life of 25 years, the analysis would run 25 one-year simulations, where each simulation considers the evolution of the grid mix, fuel prices, and other variables.

Because of the challenges of a full life-cycle cost calculation, we perform a simplified analysis, comparing the costs of a CT to the cost of a battery for a fixed system in the first year. Essentially, we find the payment for the battery that makes the two systems have equal total costs in the first year of operation. The mathematical formulation of this problem is provided in Appendix A. This approach essentially assumes that fuel prices, grid mixes, load patterns, and other factors remain the same throughout the life of the project. Several of the sensitivity cases consider variations in these factors and thus provide some insight in how the relative costs might change over time.

It is important to note that the benefits analyzed in this report occur from the perspective of a utility installing capacity on an uncongested transmission network. Storage can provide additional benefits, relieving transmission and distribution congestion and deferring new infrastructure (Akhil et al. 2015).

\footnotetext{
${ }^{2}$ For additional discussion of the application of production cost models to evaluating energy storage, see Bhatnagar and Loose (2012).
} 


\section{System Details}

For this analysis, we used a test system derived from a subset of the Western Electricity Coordinating Council (WECC) Transmission Expansion Policy Planning Committee (TEPPC) 2020 model and other publicly available data sets (WECC TEPPC 2011). The test system is large enough to be realistic but small enough to isolate the impact of changing generator flexibility parameters. The system is simulated in the PLEXOS production cost model. ${ }^{3}$ Several previous studies use this test system (Hummon et al. 2013; Palchak and Denholm 2014; Jenkin et al. forthcoming). The test system consists of two balancing authorities-Public Service Company of Colorado (PSCo) and Western Area Colorado Missouri (WACM) - and it corresponds approximately to the Rocky Mountain Reserve Group (NERC 2014). Multiple individual utilities operate within this region, which is referred to in this analysis as the Colorado test system. Utilities in this region schedule their own generators, purchase power from independent power producers, and interact with their neighbors under confidential bilateral agreements. Because many details of how this system is operated are not publicly available, this analysis assumes an optimal, least-cost dispatch. Hourly load profiles were scaled from data for 2006 to match the projected TEPPC forecast for annual load in 2020. The peak demand is 13.7 gigawatts (GW) with an annual energy demand of 78.2 terawatt-hours.

Because we are simulating a future system with increased penetration of renewable energy, we added wind generation sufficient to meet about $20 \%$ of the system's annual demand. By comparison, Colorado generated about $16 \%$ of its electricity from wind energy generation in 2014. ${ }^{4}$ Wind profiles were generated using 2006 profiles created for the Western Wind and Solar Integration Study (Lew et al. 2013). We created two PV penetration scenarios, with potential to meet about $15 \%$ and $20 \%$ of annual demand, assuming no curtailment. We retired a significant amount of generation from the base 2020 database, including about 750 megawatts (MW) of older oil- and gas-fired peaking units, and $650 \mathrm{MW}$ of coal capacity based on units with the highest heat rate. A complete list of generators in the system is provided in Appendix B.

Table 1 summarizes the generation fleet in the test system. Planning reserve values are included only to provide an approximate indication of their contribution to meeting net peak demand. The contribution of wind and solar toward the planning reserve margin depends on factors including technology, location, and penetration level. At very low penetration, a simple net load analysis indicates a fleet-wide PV capacity value of about 50\%; however, this value drops rapidly. At $15 \%$ penetration, the capacity credit of the cumulative added solar is estimated at $25 \%$. At this point, the peak net load has shifted to evening hours when the PV output is approximately zero and additional PV adds essentially no reduction in annual peak demand. ${ }^{5}$

\footnotetext{
${ }^{3}$ PLEXOS version 6.400r01, using the Xpress-MP Solver V 26.01.04 with MIP Relative gap at $0.5 \%$

${ }^{4}$ In the 12-month period ending March 2015, Colorado generated 2,081 GWh from wind compared to total in-state generation of 12,976 GWh (EIA 2015)

${ }^{5}$ In the test system, at the point where PV provides $10 \%$ of the system's energy, the annual net load peak is shifted to the evening of December 21 .
} 
Table 1. Generation Capacity of the Test System (MW)

\begin{tabular}{|l|l|l|}
\hline Generator Type & $\mathbf{1 5 \%}$ PV Case & 20\% PV Case \\
\hline Coal & 4,988 & 4,404 \\
\hline CC & 4,456 & $\begin{array}{l}4,039 \text { (500 MW added to } \\
\text { replace capacity removed } \\
\text { due to coal retirements) }\end{array}$ \\
\hline CT/internal combustion (IC)/gas steam & 3,539 & \multicolumn{2}{|l|}{} \\
\hline Hydro & $1,345$ (assumed capacity credit of 50\% or 672 MW) $)^{\text {a }}$ \\
\hline Pumped storage & 560 & $\begin{array}{l}8,198(\text { assumed capacity } \\
\text { credit of 15\%) }\end{array}$ \\
\hline Wind & 4,754 (assumed capacity credit 10\% or 475 MW) \\
\hline PV & 6,147 (assumed capacity \\
credit of 25\%) & 16,506 \\
\hline Total firm generation capacity & 16,590 & 17.2 \\
\hline $\begin{array}{l}\text { Generator planning reserve margin } \\
\text { (before new CT/battery capacity) }\end{array}$ & 17.8 & 20.8 \\
\hline $\begin{array}{l}\text { Generator planning reserve margin } \\
\text { (with 500 MW new CT/battery capacity) }\end{array}$ & 21.4 & \multicolumn{2}{|l|}{} \\
\hline
\end{tabular}

${ }^{a}$ This value is somewhat arbitrary, but reflects the fact that much of the hydro in Colorado is run-of-river with limited storage capacity or dispatchability to meet peak demand.

${ }^{\mathrm{b}}$ A previous study of wind in Colorado estimated a capacity credit of $12.5 \%$ at low penetration (Ventyx 2008). We use a slightly lower value to reflect the impact of decreased capacity credit at high penetration.

The base system (with $15 \%$ or $20 \%$ PV and before the addition of the new CT or battery) has a $17 \%-18 \%$ generation planning reserve margin. We assumed the system could call on up to $1,000 \mathrm{MW}$ of demand response in addition to conventional generation capacity, at a cost of $\$ 333 / \mathrm{MWh}$. The planning reserve margin was then increased by $500 \mathrm{MW}$ of new capacity in the form of either batteries or new combustion turbines; this brings the planning reserve margin to about 21\% (the bottom row in Table 1). For reference, the North American Electric Reliability Corporation uses a 15\% reference margin level for predominately thermal systems (NERC 2014). Because our reserve margin is higher than this value, we also evaluate a lower reserve margin in the sensitivity section.

Table 2 summarizes the characteristics of the battery and CT in the test system. The battery is not based on any specific technology but is rather intended to represent a long-duration battery with an $80 \%$ AC-AC efficiency. Our base case battery assumes a storage capacity of 2,000 MWh, or four hours of full discharge capacity (so a full charge requires five hours). This duration is based on the California Resource Adequacy Program (CPUC 2013). There is little published literature on the length of duration needed to provide firm capacity. Sioshansi et al. (2014) found that four hours would typically be insufficient to achieve the same level of capacity credit as a combustion turbine using historical market data in systems with very low levels of PV. However, Jorgenson et al. (2014) found that due to the shorter peaks created by the presence of high PV penetration, the capacity credit of storage increases. The capacity of storage needed for high capacity credit at increased PV penetration is discussed in more detail in Section 5. 
While we model the battery as a single 500-MW device, this capacity could be derived from multiple smaller devices. Because the device has no restrictions on minimum generation level and assumes constant efficiency, this assumption will have no impact on results. However, the results would be affected if we assumed behind-the-meter applications where the system operator could not optimize timing of charge/discharge or provision of ancillary services.

For the combustion turbine, we assume a state-of-the-art aeroderivative combustion generator with parameters loosely based on a GE LMS100 (GE Distributed Power 2015). ${ }^{6}$ As with batteries, this choice is not intended to reflect a particular vendor or technology. A variety of different aero-derivative turbines are available, and highly flexible internal combustion engines can also provide rapid starts and ramping with wide operating ranges (Wärtsilä and Energy Exemplar 2014).

Table 2. Operational Parameters of New Generation Capacity

\begin{tabular}{|l|l|l|}
\hline Parameter & Battery & CT \\
\hline Size & $\begin{array}{l}500 \mathrm{MW}, 2,000 \mathrm{MWh} \text { (4-hour } \\
\text { capacity) }\end{array}$ & 4 units each at 125 MW \\
\hline Efficiency & $80 \% \mathrm{AC}-\mathrm{AC}$ & $\begin{array}{l}8,800 \mathrm{Btu} / \mathrm{kWh} \text { ) at full load to } 11,640 \\
\text { Btu/kWh at 35\% load (HHV) }\end{array}$ \\
\hline $\begin{array}{l}\text { Minimum generation } \\
\text { level }\end{array}$ & $0 \%$ & $35 \%$ \\
\hline Reserves provided & $\begin{array}{l}\text { Contingency (in any state), flexibility } \\
\text { (while discharging) }\end{array}$ & Contingency, Flexibility (while operating) \\
\hline $\begin{array}{l}\text { Variable O\&M cost } \\
\text { (\$/MWh) }\end{array}$ & 0 (all O\&M assumed to be fixed) & 1.5 \\
\hline Ramp rate & Unconstrained & Full operating range in 10 minutes \\
\hline
\end{tabular}

The assumed system-wide average fuel prices are $\$ 4.95 / \mathrm{MMBtu}$ for natural gas and $\$ 1.42 /$ MMBtu for coal. We assume the variable cost of both wind and solar is zero, with no additional penalties for curtailed energy (meaning no renewable portfolio standard compliance penalties or production tax credits for renewable energy).

Three synchronized (spinning) reserve products were required: contingency, regulation, and flexibility/load following. Hourly requirements were calculated using the method discussed in Hummon et al. (2013). Contingency reserves are based on the size of the single largest unit and do not vary over time or as a function of VG penetration. Table 3 describes the overall system reserve requirements including response time. We allow both the battery and the CT to provide contingency and flexibility reserves, but the $\mathrm{CT}$ must be online to provide reserves, while the battery can provide contingency reserves during any state and flexibility reserves while discharging at any output level. We do not model contingency events, and do not consider the

\footnotetext{
${ }^{6} \mathrm{We}$ choose aeroderivative units as opposed to frame-type turbines because they are more flexible in having both short start-up times and better part-load performance, and they are more suited to providing grid flexibility in a highrenewables scenario.
} 
battery state-of-charge in its ability to provide reserves. ${ }^{7}$ In the base case we did not allow either device to provide regulation. This assumption was based on the fact that regulation is a short duration service, so provision from storage is better suited from a battery with a much smaller energy capacity (Byrne and Silva-Monroy 2012). A sensitivity case where both devices can provide regulation is considered in Section 5.

Table 3. Synchronized (Spinning) Reserve Requirement

\begin{tabular}{|l|l|l|l|}
\hline Scenario & $\begin{array}{l}\text { Generator } \\
\text { Response } \\
\text { Time } \\
\text { (Minutes) }\end{array}$ & \multicolumn{2}{|c|}{$\begin{array}{l}\text { Requirement } \\
\text { (MW - Avg/Min/Max) }\end{array}$} \\
\cline { 3 - 4 } & $\begin{array}{l}15 \% \text { PV } \\
\text { Case }\end{array}$ & 20\% PV Case \\
\hline Flexibility Up & 5 & $233 / 49 / 560$ & $260 / 49 / 716$ \\
\hline Contingency $^{8}$ & 10 & $405 / 405$ & $405 / 405$ \\
\hline Regulation Up & 20 & $162 / 78 / 325$ & $180 / 78 / 406$ \\
\hline
\end{tabular}

A considerable number of sensitivities to these base scenarios were also considered. These are discussed in detail in Sections 5 and 6, and they include:

- Additional coal retirements/lower planning reserve margin

- Carbon dioxide $\left(\mathrm{CO}_{2}\right)$ price

- Increased natural gas price

- Battery efficiency

- Battery energy capacity

- Provision of regulation reserves

\footnotetext{
${ }^{7}$ This will slightly overstate the battery value, but previous analysis indicates that this impact is small (Denholm et al. 2013a).

${ }^{8}$ Contingency is split between the two simulated balancing areas, with $225 \mathrm{MW}$ in the PSCO balancing area and $180 \mathrm{MW}$ in the WACM balancing area, based on allocating within the Rocky Mountain Reserve Sharing Group. Because we assume the battery is placed in the PSCO balancing area, it can only provide up to $225 \mathrm{MW}$ of contingency reserve.
} 


\section{Results}

We begin by comparing cases with CTs and storage in our base $15 \%$ and $20 \% \mathrm{PV}$ penetration scenarios.

\subsection{Differences in Operational Costs}

In each of the two PV penetration scenarios, we ran a case with the added CT and added battery. The difference in production cost between these scenarios is a key driver of the "allowable" cost difference between technologies.

Table 4 summarizes the production cost simulations for the four cases. It demonstrates that the storage cases result in a reduction in production costs, primarily by reducing fuel and start costs. While the overall operational benefits are positive, some of the individual categories show negative values; this is a consequence of a system co-optimizing across all sources of costs. For example, coal plants have a higher variable operation and maintenance $(O \& M)$ cost than gas plants. By increasing the use of coal, the fuel costs are reduced but at the penalty of a small increase in the costs of variable O\&M. Similarly, the addition of storage reduces curtailment from PV and wind. Curtailed energy can provide regulating reserves at no cost, so eliminating curtailment can actually increase the cost of providing regulating reserves. These issues are discussed in detail in the following sections.

Table 4. Annual Operational Costs of the Test System (M\$)

\begin{tabular}{|c|c|c|c|c|c|c|}
\hline \multirow[b]{2}{*}{ Cost Component } & \multicolumn{3}{|c|}{ 15\% PV Case } & \multicolumn{3}{|c|}{$20 \%$ PV Case } \\
\hline & $\begin{array}{l}\text { Added } \\
\text { CT }\end{array}$ & $\begin{array}{l}\text { Added } \\
\text { Storage }\end{array}$ & Difference & $\begin{array}{l}\text { Added } \\
\text { CT }\end{array}$ & $\begin{array}{l}\text { Added } \\
\text { Storage }\end{array}$ & Difference \\
\hline Fuel & $1,022.2$ & 995.7 & 26.5 & $1,016.5$ & 981.4 & 35.0 \\
\hline Start & 83.6 & 73.0 & 10.7 & 98.7 & 84.9 & 13.9 \\
\hline Variable O\&M & 115.9 & 117.0 & -1.2 & 103.5 & 104.8 & -1.3 \\
\hline Regulation payments $^{a}$ & 7.8 & 8.0 & -0.2 & 7.1 & 7.7 & -0.6 \\
\hline $\begin{array}{l}\text { Demand response } \\
\text { payments }\end{array}$ & 1.7 & 1.8 & -0.2 & 2.0 & 2.1 & -0.1 \\
\hline Total & $1,231.2$ & $1,195.5$ & 35.7 & $1,227.8$ & $1,180.8$ & 47.0 \\
\hline
\end{tabular}

${ }^{a}$ Regulation payments represent the generator-level costs of providing dynamic regulation operation. These costs are analogous to the bid price in regulation reserve markets and explained in detail by Hummon et al. (2013). The opportunity cost for regulation and other reserves are calculated internally by the model and accounted for in fuel, start, and V O\&M costs. The small increase in regulation payments is a consequence of improved system dispatch, with two major drivers. First, by reducing gas generation, storage occasionally forces coal units to provide regulation, which we assume have a higher cost of providing regulation. Second, storage reduces curtailment, which provides a zero-cost source of regulation. These small impacts are overwhelmed by the overall positive benefits of improved system dispatch 
Dividing the reduction in total costs between the CT and battery cases by the storage capacity (500 MW) provides annualized benefits of $\$ 71 / \mathrm{kW}$ and $\$ 94 / \mathrm{kW}$ of storage capacity for the $15 \%$ PV and 20\% PV case respectively. This result follows the trend observed by several previous studies that demonstrate an increase in value for storage as a function of $\mathrm{VG}$ penetration, driven in part by the increased availability of curtailed VG (Mills and Wiser 2015; Denholm et al. 2013b; Tuohy and O’Malley 2011).

The overall value produced by the battery is a combination of several factors, including load shifting by increased utilization of low-cost resources as well as reducing part-load operation of plants when providing operating reserves. Table 5 summarizes the actual battery utilization. Utilization of a generator is typically measured by the plant's generation capacity factor, which represents the energy actually generated divided by potential output if generating at full capacity over the year. However, the generator capacity factor typically does not include provision of other services. For example, a 100-MW generator can operate at $60 \mathrm{MW}$ and provide $40 \mathrm{MW}$ of upward reserves and so have only a $60 \%$ capacity factor during this period, but it can actually be fully utilized. Because a large fraction of the value of the added battery is derived from reserve provision, we consider the overall provision of services. The first row represents just the energy discharge. In the $15 \%$ case, the provision of 589 gigawatt-hours (GWh) of energy results in capacity factor of $13.5 \%$. (It should be noted that for an arbitrage only case, the theoretical limit on capacity factor would be $44 \%$ due to the need to charge and $80 \%$ efficiency). As a result, the battery only provides load leveling for a relatively small fraction (about 30\%) of its potential. The battery uses a greater fraction of its capacity providing reserves, with a total of $2,722 \mathrm{GW}-\mathrm{hr}$ of reserves in the $15 \%$ PV case, meaning $82 \%$ of the total services provided by the battery are reserves. Overall, the battery provides some type of upward capacity for nearly every hour of the year, either discharging or providing upward contingency while charging. This provision of reserves will significantly impact the value of additional battery capacity. Overall, the battery in this case provides about $82 \%$ of the contingency reserve requirements within the balancing area and $54 \%$ of the shared flexibility reserves, leaving substantially less opportunity for the next unit of battery storage. In the $20 \%$ PV case, the availability of curtailed PV increases the arbitrage opportunities, which increases the discharge (energy) capacity factor to $18.7 \%$ and decreases the fraction of total utilization for reserves to $75 \%$.

Table 5. Breakdown of Services (GWh or GW-hr) Provided by 500-MW 4-Hour Battery

\begin{tabular}{|l|c|c|}
\hline Battery Service $^{\text {a }}$ & 15\% PV Case & 20\% PV Case \\
\hline Energy & 589 & 820 \\
\hline Contingency reserves (while discharging) & 1,255 & 1,001 \\
\hline Flexibility reserves & 1,106 & 1,041 \\
\hline Discharge subtotal & 2,950 & 2,862 \\
\hline Contingency reserves (while charging) & 362 & 479 \\
\hline Total & $\mathbf{3 , 3 1 2}$ & $\mathbf{3 , 3 4 1}$ \\
\hline
\end{tabular}

a The unit "MW-hr" is sometimes applied to capacity-related services such as operating reserves. It represents a unit of capacity (MW) held for one hour. It is distinct from MWh, which is a unit of energy. 
In contrast, the new CT has much lower utilization, operating for 952 hours in the year in the $15 \%$ PV case with an energy-only capacity factor of 5.8\% and a total utilization factor (including reserves provision) of $7.2 \%$. The relatively small amount of reserves generation is due largely to the requirement that the $\mathrm{CT}$ be running at part load to provide reserves.

The majority of the costs savings that occur when adding storage is due to the reduction in fuel costs, but avoided start costs represent a significant source of value. Table 6 provides additional details about the source of fuel savings by demonstrating the change in generation. While we include the generation from storage, we do not include it in the total, as storage does not provide net generation but instead increases generation from other units. Table 6 demonstrates that replacing the new CTs with new storage reduces generation from the highest cost gas-fired generators and increases generation from lower-cost resources, including coal, solar and wind. A significant difference between the cases is the increase in generation from VG in the $20 \%$ PV case. 
Table 6. Generation Mix (GWh) in Each Scenario

\begin{tabular}{|l|r|r|r|r|r|r|}
\hline \multirow{2}{*}{ Generator Type } & \multicolumn{4}{l}{$\mathbf{1 5 \%}$ PV Case } & \multicolumn{2}{l|}{$\mathbf{2 0 \%}$ PV Case } \\
\cline { 2 - 7 } & $\begin{array}{l}\text { Added } \\
\text { CT }\end{array}$ & $\begin{array}{l}\text { Added } \\
\text { Storage }\end{array}$ & Difference & $\begin{array}{l}\text { Added } \\
\text { CT }\end{array}$ & $\begin{array}{l}\text { Added } \\
\text { Storage }\end{array}$ & Difference \\
\hline Coal & 34,871 & 35,520 & 649 & 30,060 & 30,839 & 778 \\
\hline Gas CC & 11,267 & 10,998 & -269 & 12,609 & 12,242 & -367 \\
\hline Gas CT/IC/steam & 1,069 & 939 & -130 & 1,058 & 870 & -188 \\
\hline New CT & 256 & NA & -256 & 572 & 262 & -309 \\
\hline Hydro & 3,787 & 3,789 & 2 & 3,780 & 3,783 & 3 \\
\hline PV + wind & 27,083 & 27,185 & 103 & 30,301 & 30,579 & 278 \\
\hline Other & 287 & 288 & 0 & 288 & 288 & 0 \\
\hline Existing Storage & 1,008 & 899 & -109 & 1,117 & 1,100 & -17 \\
\hline Battery & NA & 589 & 589 & NA & 820 & 820 \\
\hline Net total & $\mathbf{7 8 , 6 1 9}$ & $\mathbf{7 8 , 7 1 9}$ & $\mathbf{1 0 0}$ & $\mathbf{7 8 , 6 6 8}$ & $\mathbf{7 8 , 8 6 4}$ & $\mathbf{1 9 6}$ \\
\hline
\end{tabular}

Differences in operation can also be used to estimate the source of charging energy for storage. While determining the exact source of charging energy for storage in any given hour is difficult, the annual change in generation with the addition of storage can be "assigned" to the storage resource. Table 7 shows these results by assigning any net increase in generation with the addition of storage to the "charging" column. In this case, the differences in generation are compared to a base case without the addition of either storage or CT. This approach is only an approximation, and it should be noted that we combine solar and wind in Table 7 because they both have zero variable costs and the model does not see any difference between these resources when choosing curtailment. As a result, modeled curtailment of individual variable generators (or reductions in curtailment when adding storage) is somewhat arbitrary.

Table 7. Approximate Net "Source" of Charging Energy (percentage from Source)

\begin{tabular}{|l|c|c|}
\hline Source & 15\% PV Case & 20\% PV Case \\
\hline Coal & $84 \%$ & $74 \%$ \\
\hline Wind and solar & $16 \%$ & $26 \%$ \\
\hline
\end{tabular}

Table 7 indicates that in both cases, the majority of charging energy is derived from coal; however, the fraction derived from renewables increases in the $20 \% \mathrm{PV}$ case. The low amount of charging from VG (i.e., wind and solar) is based both on how we define the source of charging energy, as well as the relatively low curtailment rate of $\mathrm{VG}$ at this penetration. Table 8 provides the total curtailment rate for renewables in the base scenarios. In the $15 \% \mathrm{CT}$ case, less than $1 \%$ of renewables is curtailed and available for charging. Because over $99 \%$ of VG energy was already "used" by the system to displace fossil generation in the CT case, any "contractual" use of this renewable energy to charge storage would require an increase in fossil generation, with the net effect of increase in fossil generation from the use of storage. 
In the $20 \%$ case, a larger fraction of charging energy is derived from renewables. The curtailment rate of the incremental PV is significantly higher, with $18 \%$ of the additional PV curtailed, resulting in a total curtailment rate of $3 \%$ in the CT case. In both cases, the addition of storage is able to significantly reduce curtailment. ${ }^{9}$ This reduction in curtailment also explains part of the small increase in regulation payments in Table 1. We assume curtailed energy from wind and solar is able to provide upward regulation at no cost. ${ }^{10}$ In the $20 \%$ CT case, about $21 \%$ of the upward regulation requirement is provided by VG. This drops to $17 \%$ in the case with the battery, as less curtailed energy is available to provide reserves.

Table 8. VRE Curtailment (GWh/\%)

\begin{tabular}{|l|c|c|}
\hline Scenario & 15\% PV Case & $\mathbf{2 0} \%$ PV Case \\
\hline CT & $235 / 0.9 \%$ & $931 / 3.0 \%$ \\
\hline Storage & $121 / 0.4 \%$ & $615 / 1.9 \%$ \\
\hline Reduction with Storage & $113 / 48 \%$ & $316 / 34 \%$ \\
\hline
\end{tabular}

\subsection{Comparison of Capital Costs}

As discussed in Section 2, the primary metric for comparison in this analysis is battery capital cost, or the cost at which batteries provides the same total system cost as CTs, including both fixed and variable cost components. Section 4.1 provides the variable cost component, or the reduction in operational costs when replacing a new CT with a new battery. This operational value is combined with fixed cost components to provide the overall battery breakeven cost. This lower operational cost associated with the battery case means the battery can potentially be more expensive than a CT and still provide the same overall system cost to a vertically integrated utility.

Because of the challenges of a full life-cycle cost calculation (such as projecting future fuel costs and grid mixes), we perform a simplified analysis, comparing the costs of CTs to the cost of battery for a fixed system in the first year. Doing so essentially assumes that fuel prices, grid mixes, load patterns, and other factors remain the same throughout the life of the project.

To perform this analysis, we set the annualized system costs for the two systems (added CT or added battery) equal, and solve for the battery capital cost. Annualized costs include all fixed and variable costs incurred by a utility. Because the vast majority of the costs in both cases are the same, we analyze only the annualized costs of the differences between the cases, which is primarily the difference in capital and operational costs.

\footnotetext{
${ }^{9}$ At a PPA price of $\$ 60 / \mathrm{MWh}$ (corresponding to a SunShot goals) the avoided curtailment would be worth $\$ 6.8 \mathrm{M}$ and $\$ 19.0 \mathrm{M}$ in the $15 \%$ and $20 \%$ cases respectively.

${ }^{10}$ The use of wind and solar to provide upward regulation incurs an opportunity cost, as energy is typically more valuable than reserves. However, when VG is curtailed due to operational constraints, it can provide upward reserves at no opportunity cost. Furthermore, we assume that the physical provision of reserves, by performing wind turbine pitch control and active PV inverter control incurs zero cost, as compared to provision of regulation with a thermal generator, which incurs costs due to wear and tear and heat rate degradation. This is discussed in detail in Hummon et al. (2013). It is important to note that use of VG for reserves requires operator control of the resource, which may be an aggressive assumption, particularly for distributed PV. It also requires accurate forecasting for the operator to rely on the resource.
} 
Overall, the capital cost of the battery that provides an equivalent first year annualized cost is given by the relationship:

$$
C C_{B A T}=\frac{\frac{i(1+i)^{y_{C T}}}{(1+i)^{y_{C T}-1}} * C C_{C T}+F O M_{C T}-F O M_{B A T}+O P V A L_{B A T}}{\frac{i(1+i)^{y_{B A T}}}{(1+i)^{y_{B A T}-1}}}
$$

where $\mathrm{CC}$ is the capital cost, $i$ is the interest rate, $y$ is the generator lifetime and, FOM is the fixed O\&M and OPVAL ${ }_{\mathrm{BAT}}$ is the difference in operational costs between the two scenarios, which is equivalent to the operational value associated the battery $(\$ / \mathrm{kW})$ calculated in Section 4.1. The derivation of this relationship is provided in Appendix A.

Equation 1 shows there is not a simple relationship between the cost of a CT and the cost of the battery, and in addition to the operational cost savings, the relationship depends on four parameters: CT capital cost, interest rate, generator lifetime, and fixed O\&M. Assumptions for these parameters are listed in Table 8 . Because there is a wide range of estimates for the cost of new aeroderivative turbines, we use low and high values based on a range of estimates from Olsen et al. (2014). A critical element of the battery costs is the lifetime, with a shorter lifetime resulting in greater annualized payments. Because we are not analyzing a specific battery technology, and because battery lifetimes have not been well established, we consider a continuous range of battery lifetime estimates.

Table 9. Fixed Cost Components of New Generation Capacity

\begin{tabular}{|l|l|l|}
\hline Cost Component & Battery & CT \\
\hline Capital cost $(\$ / \mathrm{kW})$ & Solved for & $\$ 900($ low), \$1,500 (high) \\
\hline Interest rate $(\%)$ & $6 \%$ & $6 \%$ \\
\hline Fixed O\&M $(\$ / \mathrm{kW}-\mathrm{yr})^{\mathrm{a}}$ & $\$ 5.5$ & $\$ 15$ \\
\hline Lifetime (years) & $8-20$ & 25 \\
\hline
\end{tabular}

${ }^{a}$ The battery value is based on the fixed O\&M cost estimate for a sodium-sulfur battery (Akhil et al. 2015). The CT value is from Olsen et al. (2014). 
Figure 1 provides the overall results for the four combinations of the two PV penetration scenarios and the two assumed CT costs. The left y-axis provides the cost of the battery required to equal the $\mathrm{CT}$ in units of $\$ / \mathrm{kWh}$ of storage capacity for the total installation, while the right $\mathrm{y}$ axis translates this into an installed cost per kilowatt of capacity, which is a more typical measure for the cost of conventional generators.

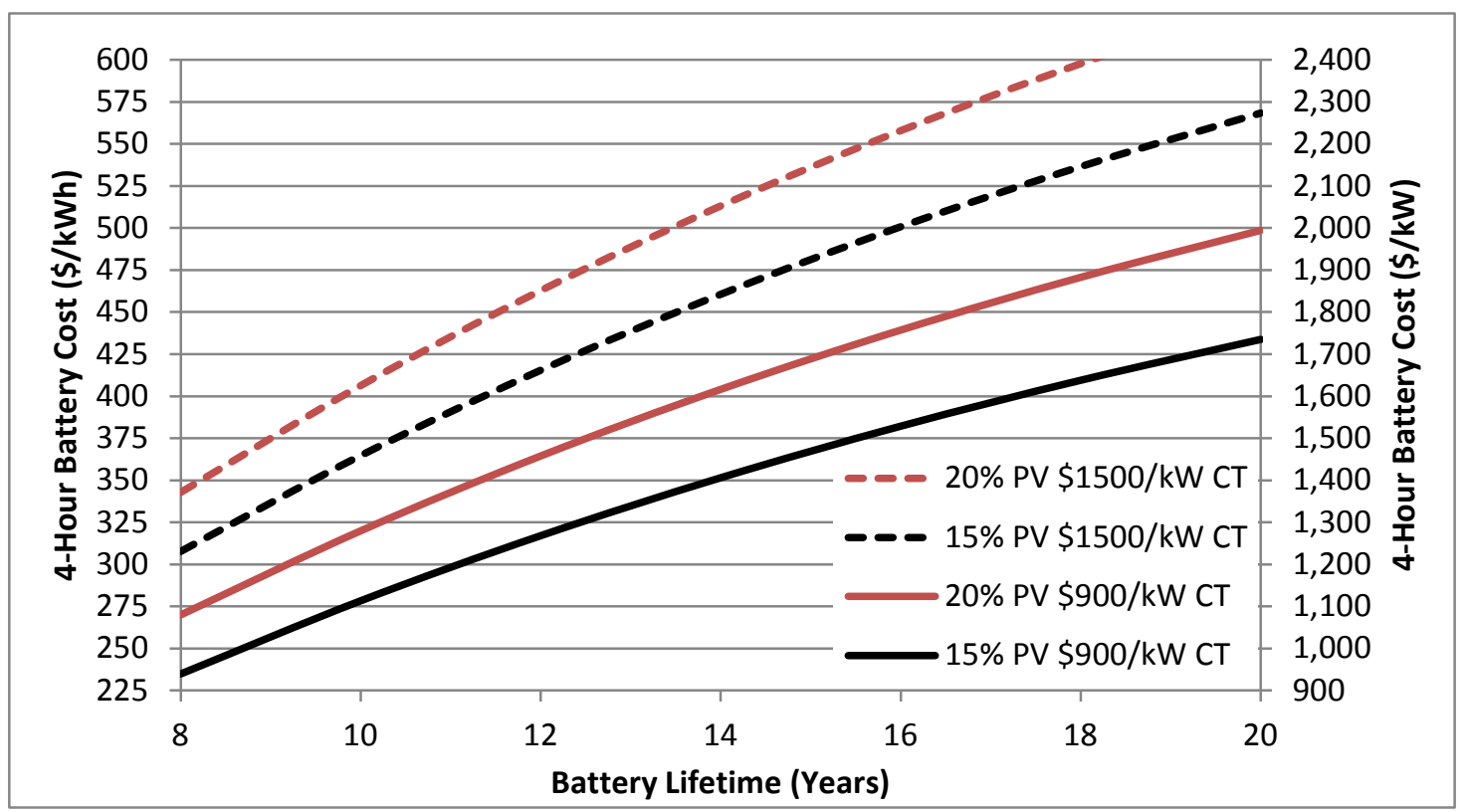

Figure 1. Battery cost that results in a system cost equivalent to that of a combustion turbine (CT) as function of lifetime for combinations of PV penetration and CT costs

Figure 1 shows the importance of battery life. In the worst-case scenario, a battery with a short (8-year) life would need a total installed cost of less than about $\$ 950 / \mathrm{kW}$ (or $\$ 235 / \mathrm{kWh}$ ) when compared to a low-cost CT $(\$ 900 / \mathrm{kW})$ in the $15 \%$ PV case. Of note is that battery costs include both the power and energy components, and they assume no residual value at the end of the life. The base case shown in Figure 1 does not consider a large array of sensitivities, several of which could increase the relative value of batteries and further increase the cost at which they could compete with CTs for new peaking capacity. 


\section{Sensitivities}

\subsection{Base Sensitivities}

The results in the previous section do not consider the consider range of grid conditions that may occur in the 2020-and-beyond timeframe. In this section, we consider several sensitivities listed in Table 10.

Table 10. Sensitivities on Base 4-Hour Battery Cases

\begin{tabular}{|l|l|}
\hline Sensitivity Name & Description \\
\hline $1.5 X$ NG price & Natural gas price increased to system-wide average of \$7.43/MMBtu \\
\hline $\mathrm{CO}_{2}$ price & $\mathrm{CO}_{2}$ cost of $\$ 46 /$ metric ton added to the dispatch price \\
\hline Reduced coal capacity & $\begin{array}{l}554 \mathrm{MW} \text { of additional coal retirements, reducing the system planning } \\
\text { reserve margin to about } 15 \%\end{array}$ \\
\hline Increased battery efficiency & Battery round-trip AC-AC efficiency of $90 \%$ \\
\hline
\end{tabular}

The $\mathrm{CO}_{2}$ price is based on the 2025 social cost of carbon ( $3 \%$ discount rate) value from the Interagency Working Group on Social Cost of Carbon (IWG 2015). The improved battery efficiency could result from some combination of alternative battery technologies (Akhil et al. 2015 ) or the additional benefits of avoided losses in distribution networks. For example, an analysis by Nourai et al. (2008) found that distribution-sited batteries could increase effective battery round-trip efficiency by about $10 \%$ by avoiding resistive $\left(I^{2} R\right)$ losses, which peak during periods of high demand. Table 11 provides the results of these cases, expressed as both the total reduction in operational costs $(\mathrm{M} \$)$ as well as the cost per $\mathrm{kW}$ with the addition of a 500-MW battery.

Table 11. Reduction in Annual Operational Costs of Replacing a 500-MW CT with 500 MW of 4-Hour Energy Storage (M\$ and \$/kW)

\begin{tabular}{|l|l|l|}
\hline Scenario (all 4-hr batteries) & 15\% PV Case & 20\% PV Case \\
\hline Base & $35.7 / 71.4$ & $47.0 / 94.0$ \\
\hline 1.5X NG price & $46.3 / 92.6$ & $65.9 / 131.9$ \\
\hline $\mathrm{CO}_{2}$ price & $22.2 / 44.3$ & $37.6 / 75.2$ \\
\hline Reduced coal capacity & $39.5 / 78.9$ & $42.6 / 85.2$ \\
\hline Increased battery efficiency & $38.4 / 76.9$ & $50 . / 99.9$ \\
\hline
\end{tabular}

The sensitivity results vary widely but all are strongly impacted by the basic origin of value for the storage plant. As discussed in Section 4, the storage plant derives its value by a combination of load shifting, improved efficiency of dispatch by provision of reserves, and avoided starts. In the case of load shifting/energy arbitrage, value is produced largely by charging with off-peak coal generation and displacing gas. The first two sensitivity cases significantly impact the arbitrage opportunity. Increasing natural gas prices increases the on-peak prices, which increases the value of storage by $30 \%-40 \%$. Alternatively, the $\mathrm{CO}_{2}$ cost case increases both on and offpeak prices, but because coal has a greater carbon content, it increases off-peak prices more than 
on-peak prices, which decreases arbitrage opportunities and ultimately decreases the value of storage. $^{11}$ The decrease in value is less in the $20 \%$ PV case $(-20 \%$ compared to $-38 \%$ in the $15 \%$ PV case), as there is a greater fraction of charging from zero-carbon renewables. As has been noted in previous studies, the interaction of storage and carbon emissions is complicated. While storage can act as a renewable-enabling technology, its significant benefits as a carbon reduction technology would not appear until there would otherwise be enough curtailed renewables to provide a large amount of zero-carbon charging energy (Tuohy and O'Malley 2011; Koritarov et al. 2014; Denholm et al. 2013b). We find similar results in this analysis. In the base 15\% PV case, the addition of storage produces a small (0.5\%) increase in $\mathrm{CO}_{2}$ emissions, while the $20 \%$ PV base case produces a small $(0.1 \%)$ decrease in emissions.

Similarly, the results of the reduced coal capacity case are mixed, with the $20 \%$ PV case showing a reduction in value due to the reduced availability of low-cost charging from coal. The increased battery efficiency case results in a $8 \%-10 \%$ increase in value, with the $20 \% \mathrm{PV}$ case having a greater increase due to the greater use of the device for arbitrage, as discussed in Section 4.

The values in Table 11 can be applied to the capital cost equation in Section 4 to derive different breakeven costs for energy storage. Instead of plotting the full set of results for both levels of PV penetration and CT costs, Figure 2 provides an example that demonstrates the impact of the sensitivities. In this example, we show the results for the $15 \% \mathrm{PV}$ case but use a CT cost of $\$ 1,200 / \mathrm{kW}$ (midway between the low and high values used previously) as a comparison point.

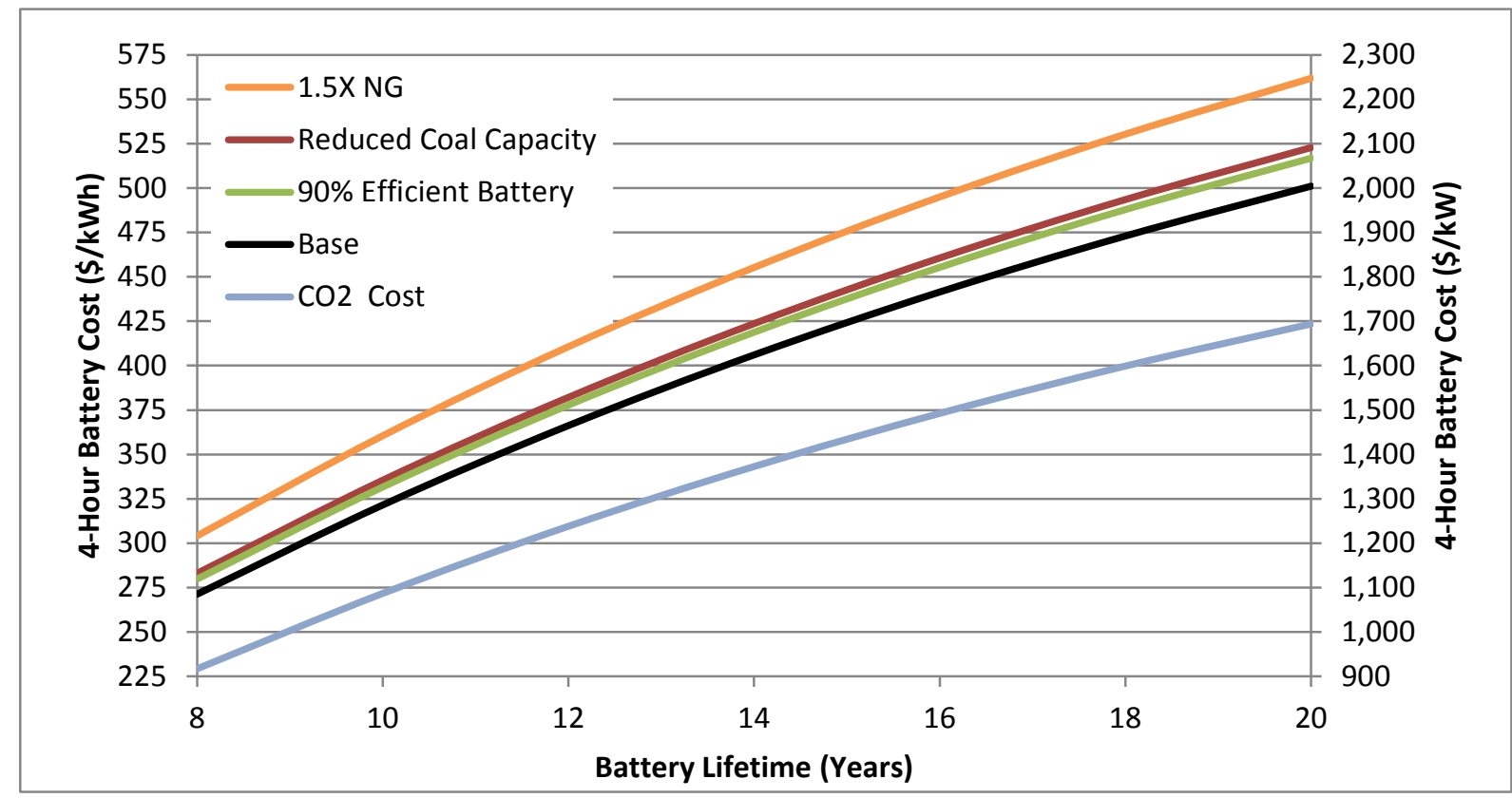

Figure 2. Battery cost that results in a system cost equivalent to a $\$ 1,200 / \mathrm{kW}$ CT as function of lifetime for the $15 \%$ PV penetration sensitivity cases

\footnotetext{
${ }^{11}$ For example, in the $15 \% \mathrm{PV} \mathrm{CO}_{2}$ case, the total discharge capacity decreases to $8.6 \%$ compared to $13.5 \%$ in the base case.
} 
Figure 3 provides the same information, but reformatted to show the cost adder or the additional cost (measured on a $\$ / \mathrm{kW}$ basis) that a battery must achieve to have an equal system cost compared to the $\$ 1,200 / \mathrm{kW} \mathrm{CT}$.

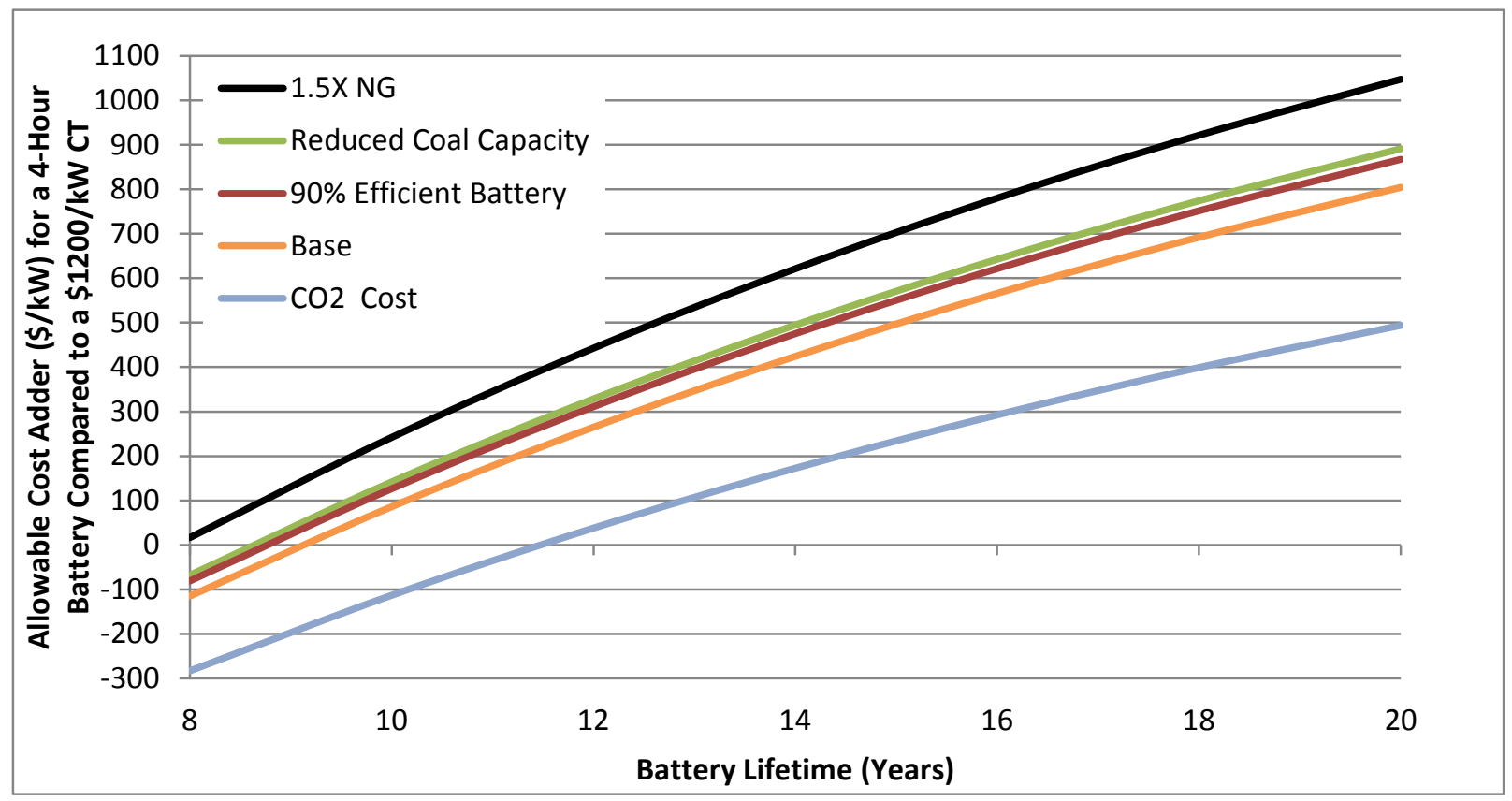

Figure 3. Additional cost of a battery $(\$ / \mathrm{kW})$ that results in a system cost equivalent to a $\$ 1,200 / \mathrm{kW}$ CT as function of lifetime for the $15 \%$ PV penetration sensitivity cases

\subsection{Provision of Regulation Reserves}

Our base case assumes that neither the new CT nor the battery provides regulation reserves, based in part on the assumption that regulation storage devices will likely be short-duration batteries or short-duration devices such as flywheels. However, long-duration batteries can easily provide regulation services, so we provide a case where we allow both the CT and battery to provide regulation.

\section{Estimating Regulation Make-Up Energy}

We assume that regulation is net-energy neutral in each one-hour simulation interval (meaning there will be no net generation from a resource providing regulation). However, the constant change in generator or battery will impose additional costs. For the CT, we added a $\$ 4 / \mathrm{MW}-\mathrm{hr}$ "bid" cost to reflect the additional wear-and-tear and fuel costs associated with constant output changes, based on the methodology applied by Hummon et al. (2013).

For batteries, we added a "make-up" energy cost. Even though we assume regulation is netenergy neutral over time, in any given dispatch interval real energy will be consumed or produced by the storage device. This will produce a net consumption of energy by the storage device due to round-trip efficiency losses. Because we do not simulate the actual dispatch of storage devices providing regulation, we make a set of simplifying assumptions to address the energy consumed. The energy consumed by a device providing regulation is the product of two factors: the fraction of reserve capacity actually used to provide real energy and efficiency 
losses. The first factor, has been referred to as the "regulation energy use ratio" (Ellison et al. 2012) or the "dispatch-to-contract ratio" (Kempton and Tomic 2005), and it depends on the actual amount of energy that flows through the device when called to provide regulation services, quantified by the regulation signal actually sent to the storage device. This actual energy is multiplied by the loss rate to produce the amount of energy actually consumed by the storage device when providing reserve services. Previous estimates of the dispatch-to-contract ratio include 10\% (Xi and Sioshansi), 14\% (Ferreira 2013), and 25\% (Ellison et al. 2012); we evaluate cases with ratios of $10 \%$ and $25 \%$. The efficiency loss rate is $20 \%$, based on a net round-trip efficiency of $80 \%$.

As a result, for each hour, a storage device providing $100 \mathrm{MW}$ of regulation consumes 2.0 or 5.0 MWh of energy. However, we also adjust the make-up energy requirement based on the discharge of the battery to provide energy during each hour. A battery that is discharging can provide regulation by varying output around its setpoint without make-up energy. For example, when the $500-\mathrm{MW}$ battery is discharging at $60 \mathrm{MW}$ during an hour, it can also provide up to $60 \mathrm{MW}$ of regulation by operating between $120 \mathrm{MW}$ and $0 \mathrm{MW}$ during the same hour. As long as regulation is at net zero during that hour, the device will provide the same amount of energy and therefore require no additional make-up energy. ${ }^{29}$ However, any regulation provided that exceeds the average discharge will require make-up energy at the same rate as the reserves-only device. For example, a 500-MW device discharging at $20 \mathrm{MW}$ could provide only $20 \mathrm{MW}$ of regulation without any make-up energy and another $480 \mathrm{MW}$ of regulation that would require make-up energy.

We used the marginal energy price and assume the storage device providing reserves must effectively purchase energy at this rate for "make-up energy" associated with losses while providing reserves. This price was multiplied by the effective energy consumption rate and loss rate and was performed in post-processing. A disadvantage of this approach is that it removes this loss rate from the dispatch optimization in the model, somewhat reducing the efficiency of the system as a whole.

\section{Results}

Figure 4 provides the results, comparing the breakeven cost of a battery providing regulation, compared to the base case where the battery does not provide regulation. As with Figure 2, we use a single CT cost $(\$ 1,200 / \mathrm{kW})$ for clarity. Allowing the battery to provide regulation increases the breakeven cost of the battery by $\$ 40 / \mathrm{kWh}-\$ 150 / \mathrm{kWh}$. The dispatch-to-contract ratio has little impact on this value, in part because the battery provides a significant fraction of regulation while discharging for load leveling, reducing the make-up energy requirement. It is important to note that this analysis does not consider any impact on battery life that may result from more frequent cycling. However, the shift in cost curve can be used as an indicator of acceptable lifetime degradation. Instead of a higher cost compared to the base battery, a battery providing regulation could alternatively have a shorter life. 


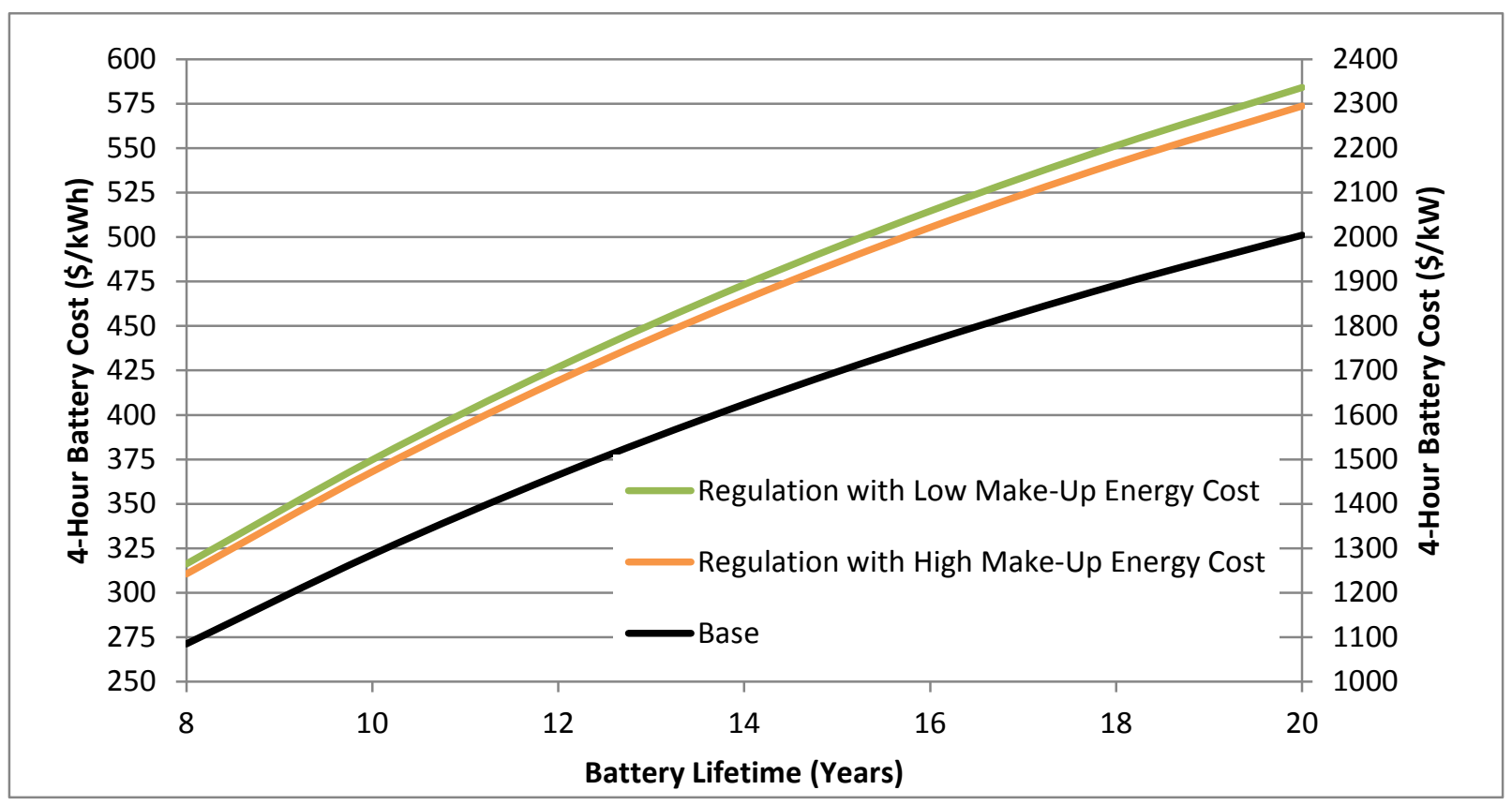

Figure 4. Battery cost that results in a system cost equivalent to a $\$ 1,200 / \mathrm{kW}$ CT as function of lifetime for the $15 \%$ PV case where both the CT and battery can provide regulation reserves

It should also be noted that the battery in this scenario provides $98 \%$ of the regulation requirement in the system, which reduces the price of regulation to zero during $72 \%$ of all hours. 


\section{Impact of Renewables on Required Battery Capacity}

A key element of this analysis is the assumption that a four-hour battery can replace a CT by providing firm capacity. A CT can run continuously for many hours or days, with availability limited only by fuel supply and need for maintenance. A battery is limited by storage capacity; however, peak periods are highly predictable and last only a few hours, so it is reasonable to expect that storage plants can be scheduled to have energy available to meet peak demand. Historically, utilities have relied on pumped storage with many hours of capacity for provision of peak capacity, and Sioshansi et al. (2013) suggest that in a system with very low PV, eight hours of capacity may be needed to achieve the same level of capacity credit as a combustion turbine. Because of the high costs of battery energy storage, it is important to consider how much capacity is needed and whether shorter-duration batteries could provide the same level of service under increased penetration of $\mathrm{VG}^{12}$ While we do not perform a full reliability analysis in this work, previous analysis has demonstrated that PV acts to "narrow" peak demand periods (Jorgenson et al. 2014). This is demonstrated in Figure 5, the net load for two days in the studied system with zero and $15 \%$ penetration of PV.

${ }^{12}$ This general concept has also been referred to as the "minimum buffer energy storage capacity" (Perez et al. 2008). 


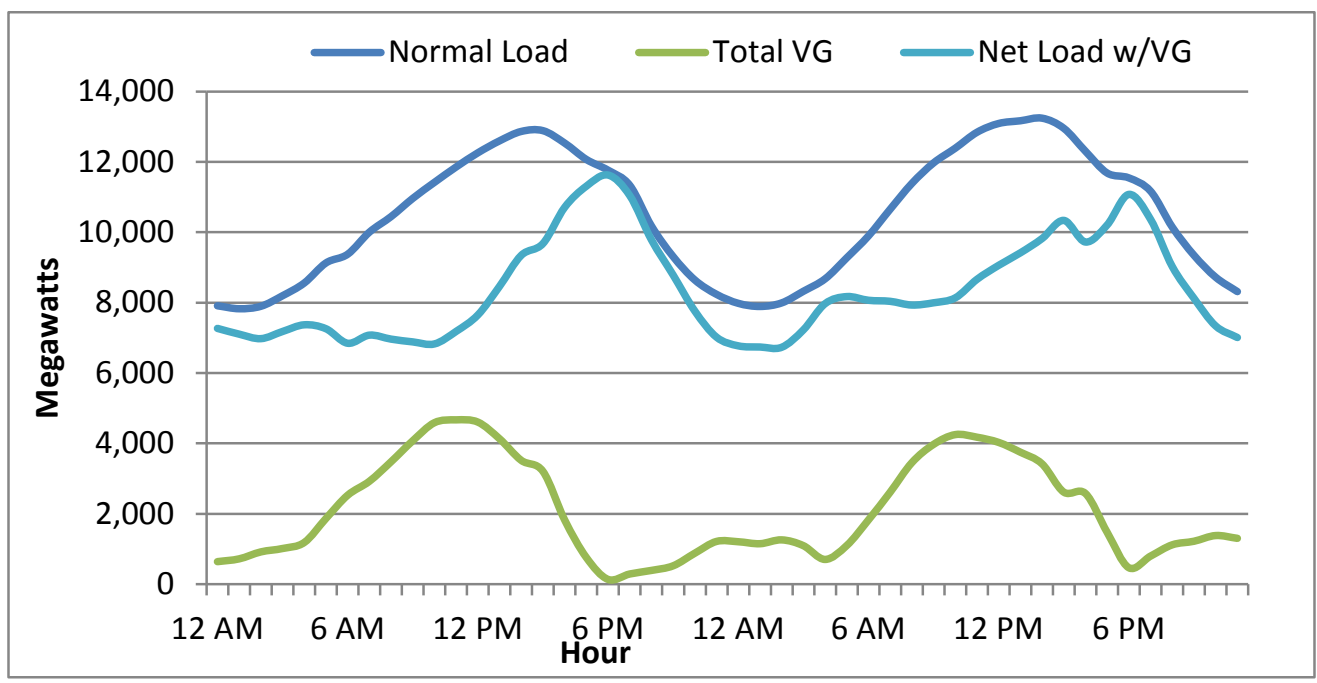

(a) July 30-31

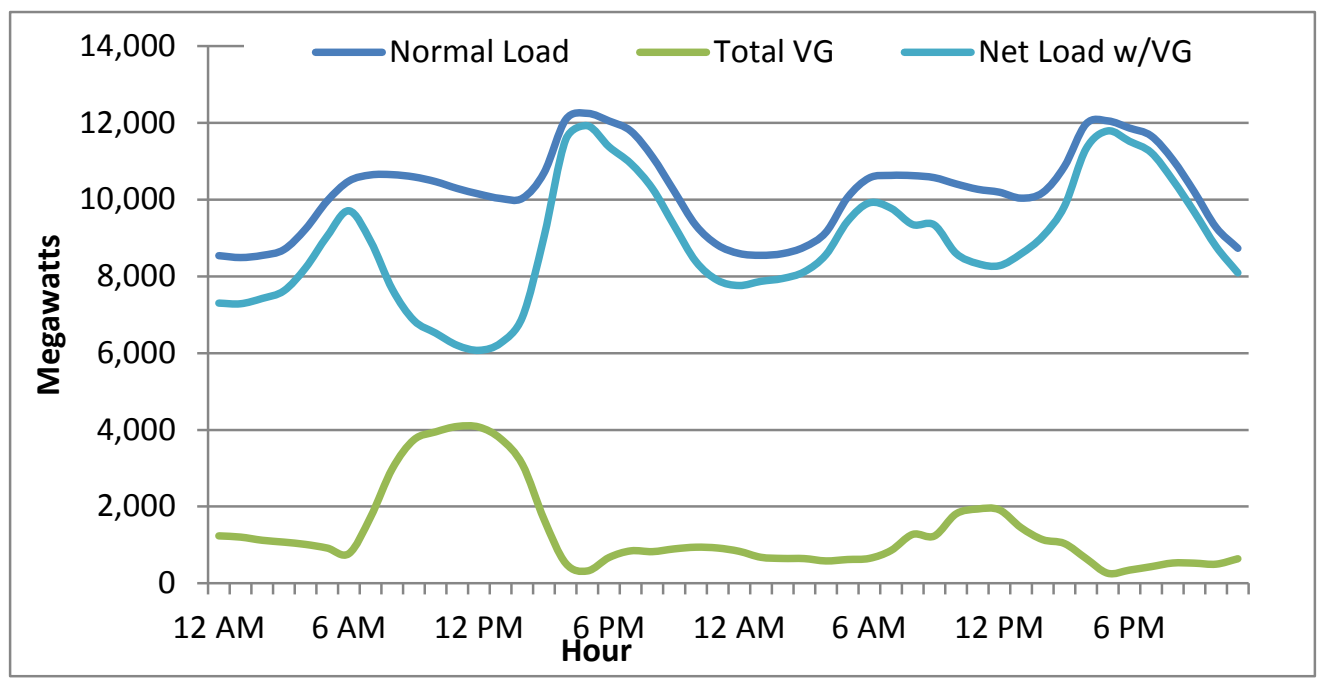

(b) December 21-22

Figure 5. Normal load (no VG) and net load with $20 \%$ wind and $15 \%$ PV 
To explore this issue in detail, we measured the length of the peak demand period as a function of PV penetration. Figure 6 demonstrates this impact for two days (one in summer, one in winter), both with and without the added wind and solar. The figure for each day shows the load with and without added VG, as well as the amount of energy needed to be produced by storage to reduce the peak demand by $500 \mathrm{MW}$, which is represented by the shaded area under the demand curves.

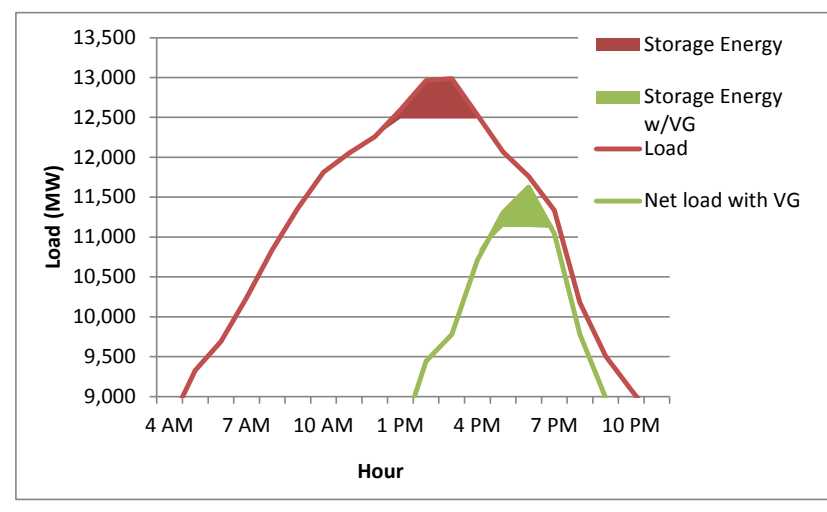

(a) July 30

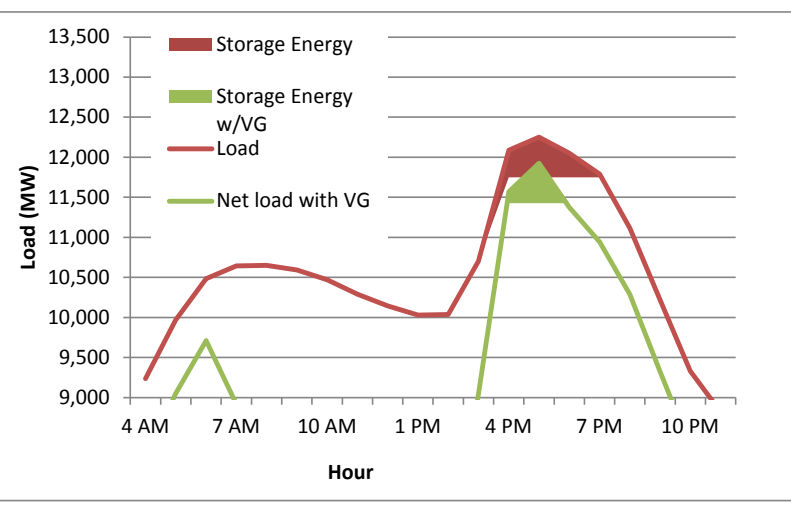

(b) December 21

Figure 6. Narrowing of net peak and amount of storage needed to deliver a 500-MW peak demand reduction on July 30 and December 21

In the summer case, the normal demand would require about 1,336 MWh of stored energy, or 2.7 hours of capacity for a 500-MW battery. This amount is reduced to $684 \mathrm{MWh}$ (1.4 hours of capacity) in the case with the added VG. Likewise, the winter case requires 2.4 hours of capacity to reduce demand by $500 \mathrm{MW}$ without VG, and about 1.3 hours with VG.

We repeated this analysis for all days containing the highest 100 hours of demand to identify the maximum storage duration needed for a 500-MW battery as a function of VG penetration. We also considered the requirement for a 1,000-MW battery. Figure 7 shows the results. At zero penetration of $\mathrm{PV}$, over four hours of battery capacity is needed to reliably shift load by 500 MW, assuming an optimally scheduled battery (requiring perfect foresight of demand during the peak period). Note that this does not mean that the battery operates at full output at four hours; the battery output is assumed to follow the shape of demand curve, often discharging at partial output. As PV penetration increases, the battery capacity requirement actually increases as PV has high load coincidence and clips the peak. This actually widens the peak period a small amount. However beyond $10 \%$ penetration, PV begins to narrow the peak demand period, decreasing the battery capacity needed, to the point where about two hours of storage capacity is needed in the $15 \%$ and $20 \%$ cases analyzed here. As penetration of storage increases, more storage is needed, as storage needs to meet the wider part of the demand curve, indicated by the need for about 5.5 hours of storage in the zero PV case with a 1,000-MW battery. It should also be noted that the incremental operational value of the larger device will be less due to saturation of the operating reserve requirement and reduced arbitrage opportunities (Denholm et al. 2013c). 


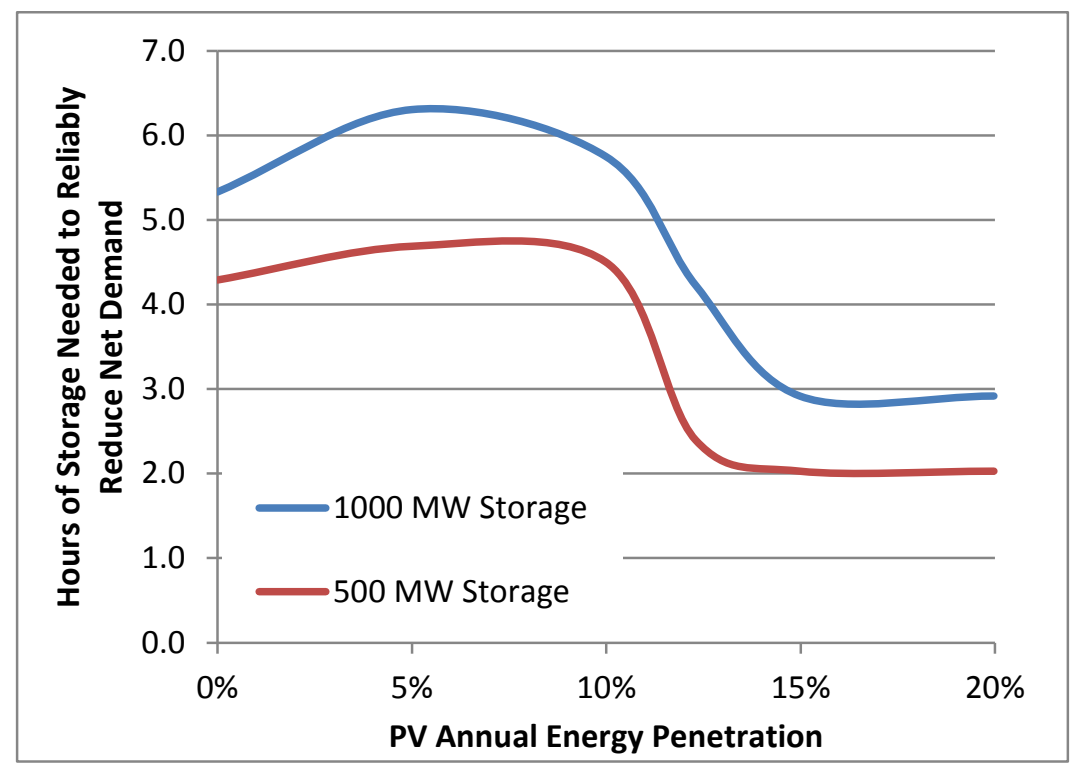

Figure 7. Hours of storage needed to reduce peak demand by $500 \mathrm{MW}$ and 1,000 MW as a function of PV penetration

While the results in Figure 7 require perfect foresight of both the load and PV patterns, even with imperfect foresight, it is possible that reducing the needed capacity to fewer than four hours could still maintain high capacity credit. Reducing the size of the battery will of course reduce the operational value of the battery due to lower arbitrage opportunity, but this may be compensated by the reduction in cost. To examine this possible tradeoff, we evaluated the impact of a battery with two hours of capacity. This case also provides a simple way to examine the impact of uncertainty. A utility could install a three-hour battery but only commit two hours of capacity, leaving one hour to address uncertainty in load and PV availability. In the $15 \%$ PV case, the operational savings of the two-hour device equal to $\$ 34.2$ million is only about $4 \%$ less than the four-hour device value of $\$ 35.7$ million (primarily due to the fact that the devices primarily provide operating reserves instead of load-shifting). As a result, there is not a significant penalty with deploying a smaller battery. In the $20 \%$ PV case, the shorter duration battery loses some of the opportunity to shift curtailed solar, so the two-hour battery value drops to $\$ 39.0$ million, a decrease of about $16 \%$ compared to the $\$ 47.0$ million value of the fourhour battery. 
Figure 8 demonstrates the installed cost of a battery needed to equal the annualized cost of a CT at the two CT costs for the $15 \%$ PV case. (To estimate the costs in the $20 \%$ case, shift the curves upward by about $5 \%$. While the value of the two-hour battery drops at by a higher percentage than in the $15 \%$ case, the $20 \%$ battery case starts with a higher value and so still has a greater overall value). In this figure, only two hours of the battery are actually dispatched by the system operator; the three-hour battery assumes an extra hour of capacity is held to address load and PV uncertainty. In reality, the three-hour battery would provide additional benefits when actually dispatched to address forecast error; additional analysis is needed to assess the impact of forecast error and other uncertainty on how a storage plant would be operated to maintain peak capacity requirements. ${ }^{13}$

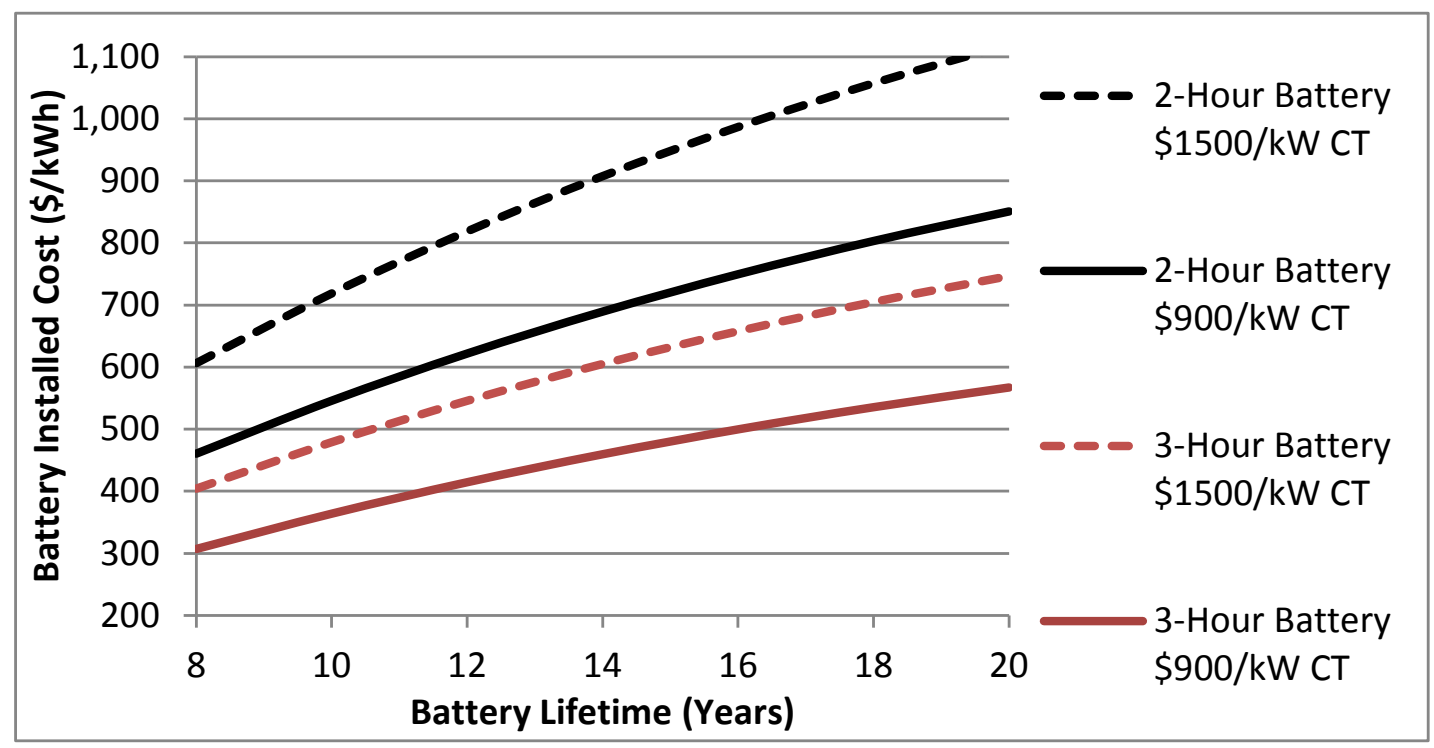

Figure 8. Breakeven battery cost $(\$ / k W h)$ in the $15 \%$ PV case where only two hours of the battery is dispatched

\footnotetext{
${ }^{13}$ This issue is also noted by CPUC (2014).
} 


\section{Market Challenges}

The framework of this analysis is an "integrated resource planning" type of approach where a single planning authority determines the optimal mix of generation capacity. This approach is associated with vertically integrated utilities in regions without restructured markets, primarily in the southeastern United States and the Western Interconnection (including the area studied in this analysis), and excluding most of California. Deployment of storage in regions with restructured wholesale markets introduces a number of considerations, particularly if storage is operated by "merchant" storage developers who may derive a large fraction of revenues from energy and ancillary service markets. As has been noted, there are several important limitations to storage plants receiving the full market value of energy storage, and these are discussed extensively by Koritarov et al. (2014), Sioshansi et al. (2012), and Bhatnagar et al. (2013). These limitations include several factors observed in this analysis.

As noted in Table 4, a large fraction of the benefits of storage (typically in the range of $25 \%-$ $35 \%$ in the cases analyzed) is derived from avoided starts. Power plant start costs, and associated benefits of avoiding start costs, are not reflected in locational marginal prices in restructured wholesale markets. ${ }^{14}$ As a result, it is difficult for storage to be compensated for the multiple benefits it provides. This issue is compounded by the need for a system operator to optimize the storage resource to minimize overall system production cost. In U.S. wholesale markets, only PJM allows the system operator to completely optimize the charge/discharge patterns of storage operation (Koritarov et al. 2014). All other U.S. electricity markets require some degree of selfscheduling by storage operators. The timing of avoided starts cannot be predicted by a storage plant owner who does not have complete knowledge of system conditions. Another factor is the need for "make-whole" payments if storage is completely optimized by the system operator. In some cases the benefits to the system of storage avoiding starts, load shifting, and provision of ancillary services will result in the net effect of storage losing money based on its charge/ discharge cycle, particularly after the impact of storage plant operation on wholesale prices.

While the prices produced by our PLEXOS simulation do not reflect true market prices - they do not including bidding strategies or scarcity pricing - they can provide some indication of the challenges of revenue recovery for merchant storage. We examined the net revenue for each 24hour period where revenue is the sum of revenue from energy and ancillary services (equal to provision in MW multiplied by the price) and the charging costs. We found that in about $50 \%$ of days the revenue was less than the value provided by the system (defined as reduction in production cost) and was actually negative in 20 days of the year.

Finally, merchant storage plant developers must consider the potential price suppression effects on both energy and reserves prices. While not unique to energy storage, these effects may ultimately provide a disincentive to storage and other technologies that can efficiency provide ancillary services, where the limited size of the market makes them particularly sensitive to relatively small additions of capacity. In the PLEXOS simulations, the $500 \mathrm{MW}$ of storage capacity significantly exceeds the spinning contingency reserve requirement, and the prices for contingency reserves are zero for $75 \%$ and $68 \%$ of all hours in the $15 \%$ and $20 \% \mathrm{PV}$ cases with

\footnotetext{
${ }^{14}$ For additional discussion of capturing start costs in energy prices and proposed market mechanisms to address this issue see "Extended Locational Marginal Pricing," (MISO), https://www.misoenergy.org/Library/Repository/ Communication\%20Material/Strategic\%20Initiatives/ELMP\%20FAQs.pdf.
} 
added storage. Combined with the additional benefits of transmission and distribution deferral, which cannot be easily captured by a single entity in restructured energy markets, these issues suggest further examination of storage as a regulated asset, as previously discussed by Sioshansi et al. (2009) and Koritarov et al. (2014). 


\section{Conclusions}

At high penetration of PV, retiring generators will need to be replaced with new sources of capacity. When properly scheduled, long-duration (several hours of capacity) batteries provide an alternative to combustion turbines for meeting peak capacity requirements. Even when compared to state-of-the-art highly flexible combustion turbines, batteries can provide a greater operational value, as is reflected in a lower system-wide production cost. This increase in value means that depending on battery life, batteries can have a higher cost on a $\$ / \mathrm{kW}$ basis compared to a combustion turbine of equal capacity. Batteries with a lifetime of less than 10 years will likely need a cost similar to CTs, while a 20 -year life battery could have a cost approaching twice that of a CT. An important caveat to this result is that the battery considered in this analysis was sized to meet about 4\% of the systems' peak net demand; larger batteries will have lower marginal value as there are fewer opportunities for time-shifting and provision of reserves.

In addition to lifetime, the cost premium for batteries is highly sensitive to a variety of other factors, including natural gas costs, PV penetration, and grid generation mix. An additional factor to consider is the effect of PV penetration on needed battery capacity. We consider a 4hour battery as the base size needed to provide the same level of reliability as a CT. However, as PV penetration increases, decreased peak-period windows may reduce the amount of battery energy capacity needed to reliably meet peak demand. Further assessment of actual battery size needed to provide system-wide capacity is needed, especially considering forecast uncertainty.

A critical issue when comparing batteries and combustion turbines is their treatment in the marketplace. This analysis assumes a traditional vertically integrated least-cost planning framework. Additional analysis is needed to test revenue requirements for peaking resources and examine whether batteries can compete with traditional generation in restructured wholesale markets. 


\section{References}

Akhil, A.A., G. Huff, A.B. Currier, B.C. Kaun, D. M. Rastler, S.B. Chen, A.L. Cotter, D.T.

Bradshaw, and W. D. Gauntlett. 2013. DOE/EPRI 2013 Electricity Storage Handbook in

Collaboration with NRECA. SAND2015-1002. Albuquerque: Sandia National

Laboratories. http://www.sandia.gov/ess/publications/SAND2013-5131.pdf.

Bhatnagar, D., A. Currier, J. Hernandez, O. Ma, and B. Kirby. 2013. Market and Policy Barriers to Energy Storage Deployment: A Study for the Energy Storage Systems Program. SAND20137606. Albuquerque: Sandia National

Laboratories. http://www.sandia.gov/ess/publications/SAND2013-7606.pdf.

Bhatnagar, D., Loose, V. (2012) Evaluating Utility Owned Electric Energy Storage Systems: A Perspective for State Electric Utility Regulators SAND2012-9422. Albuquerque: Sandia National Laboratories.

Byrne, R. H., and C.A. Silva-Monroy. 2012. Estimating the Maximum Potential Revenue for Grid Connected Electricity Storage: Arbitrage and Regulation. SAND2012-3863. Albuquerque: Sandia National Laboratories. http://www.sandia.gov/ess/publications/SAND2012-3863.pdf.

CPUC (California Public Utilities Commission). 2014. "Comments and Proposal of the California Independent System Operator Corporation." Rulemaking 14-10-010. San Francisco: California Public Utilities Commission. http://www.caiso.com/Documents/ Jan16 2015 Comments Proposal ResourceAdequacy R14-10-010.pdf.

2013. Qualifying Capacity and Effective Flexible Capacity Calculation Methodologies for Energy Storage and Supply-Side Demand Response Resources. Draft Staff Proposal. Resource Adequacy Proceeding R.11-10-023. San Francisco: California Public Utilities Commission - Energy Division. http://www.cpuc.ca.gov/NR/rdonlyres/59531E27-5A74-4E478551-0FBAB2DB6B0D/0/QCandEFCMethodologies_ESandSupplySideDR.PDF.

Cutter, Eric, Ben Haley, Jeremy Hargreaves, and Jim Williams. 2014. "Utility scale energy storage and the need for flexible capacity metrics." Applied Energy 124:274282. http://dx.doi.org/10.1016/j.apenergy.2014.03.011.

Denholm, P., Y. Wan, M. Hummon, and M. Mehos. 2013a. Analysis of Concentrating Solar Power with Thermal Energy Storage in a California 33\% Renewable Scenario. NREL Report No. TP-6A20-58186. Golden, CO: National Renewable Energy Laboratory.

Denholm, P., J. Jorgenson, M. Hummon, D. Palchak, B. Kirby, O. Ma, and M. O’Malley. 2013b. Impact of Wind and Solar on the Value of Energy Storage. NREL/TP-6A20-60568. Golden, CO: National Renewable Energy Laboratory. http://www.nrel.gov/docs/fy14osti/60568.pdf.

Denholm, P., J. Jorgenson, M. Hummon, T. Jenkin, D. Palchak, B. Kirby, O. Ma, and M. O'Malley. 2013c. The Value of Energy Storage for Grid Applications. NREL/TP-6A20-58465. Golden, CO: National Renewable Energy Laboratory. http://www.nrel.gov/docs/fy13osti/58465.pdf. 
EIA 2015. Electric Power Monthly data for March 2015 http://www.eia.gov/electricity/monthly/ http://www.eia.gov/electricity/monthly/pdf/epm.pdf

EIA (Energy Information Administration). 2015. Electric Power Monthly: With Data for March 2015. Washington, D.C.: Energy Information Administration. http://www.eia.gov/ electricity/monthly/current year/may2015.pdf.

Ellison, J.; Bhatnagar, D.; Karlson, B. (2012). Maui Energy Storage Study. SAND2012-10314. Albuquerque, NM: Sandia National Laboratories.

EPRI (Electric Power Research Institute). 2013. Cost-Effectiveness of Energy Storage in California: Application of the Energy Storage Valuation Tool to Inform the California Public Utility Commission Proceeding R. 10-12-007. Palo Alto, CA: Electric Power Research Institute. http://www.epri.com/abstracts/Pages/ProductAbstract.aspx?ProductId=0000000030020 01162.

Ferreira, S.R.; Rose, D. M.; Schoenwald, D.A.; Bray, K.; Conover, D.; Kintner-Meyer, M.; Viswanathan, V. (2013), Protocol for Uniformly Measuring and Expressing the Performance of Energy Storage Systems. SAND2013-7084. Albuquerque, NM: Sandia National Laboratories.

GE Distributed Power. 2015. "Flexible Power: LMS100." GEA14355H. Cincinnati: GE Power \& Water Distributed Power. https://www.ge-distributedpower.com/component/

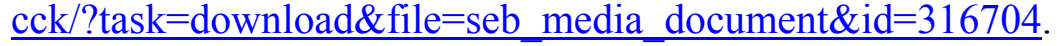

Hummon, Marissa, Paul Denholm, Jennie Jorgenson, David Palchak, Brendan Kirby, and Ookie Ma. 2013. Fundamental Drivers of the Cost and Price of Operating Reserves. NREL/TP-6A2058491. Golden, CO: National Renewable Energy Laboratory. http://www.nrel.gov/docs/fy13osti/ 58491.pdf.

Interagency Working Group on Social Cost of Carbon. 2015. Technical Support Document: Technical Update of the Social Cost of Carbon for Regulatory Impact Analysis Under Executive Order 12866. Washington, D.C.: The White House. https://www.whitehouse.gov/sites/default/ files/omb/inforeg/scc-tsd-final-july-2015.pdf.

Jenkin, T.,V. Diakov, E. Drury, B. Bush, P. Denholm, J. Milford, D. Arent, R. Margolis, and R, Byrne. (2013). Use of Solar and Wind as a Physical Hedge against Price Variability within a Generation Portfolio. NREL TP-6A20-59065. Golden, CO: National Renewable Energy Laboratory.

Jorgenson, J., P. Denholm, and M. Mehos. 2014. Estimating the Value of Utility-Scale Solar Technologies in California Under a 40\% Renewable Portfolio Standard. NREL/TP-6A2061685. Golden, CO: National Renewable Energy Laboratory. http://www.nrel.gov/docs/fy14osti/ 61685.pdf.

Kempton, W.; Tomic, J. (2005) "Vehicle-to-grid power fundamentals: Calculating capacity and net revenue." Journal of Power Sources (144); pp. 268-279. 
Koritarov, V., T. D. Veselka, J. Gasper, B. M. Bethke, A. Botterud, J. Wang, M. Mahalik, Z. Zhou, C. Milostan, J. Feltes, Y. Kazachkov, T. Guo, G. Liu, B. Trouille, P. Donalek, K. King, E. Ela, B. Kirby, I. Krad, and V. Gevorgian. 2014. Modeling and Analysis of Value of Advanced Pumped Storage Hydropower in the United States. ANL/DIS-14/7. Argonne, IL: Argonne National Laboratory. http://www.ipd.anl.gov/anlpubs/2014/07/105786.pdf.

Jenkin, T., V. Diakov, P. Denholm, D. Feldman, R. Margolis. Forthcoming. Examining the Sensitivity of Generator Capital Recovery to Variable Renewable Energy Penetration and Other Factors in Restructured Electricity Markets.

Lew, D., G. Brinkman, E. Ibanez, A. Florita, M. Heaney, B.-M. Hodge, M. Hummon, G. Stark, J. King, S.A. Lefton, N. Kumar, D. Agan, G. Jordan, and S. Venkataraman. 2013. The Western Wind and Solar Integration Study Phase 2. NREL/NREL/TP-5500-55588. Golden, CO: National Renewable Energy Laboratory. http:/www.nrel.gov/docs/fy13osti/55588.pdf.

Lyons, Chet. 2014. Guide to Procurement of Flexible Peaking Capacity: Energy Storage or Combustion Turbines? Energy Strategies Group.

Madaeni, S.H., R. Sioshansi, and P. Denholm. 2013. "Comparing Capacity Value Estimation Techniques for Photovoltaic Solar Power.” IEEE Journal of Photovoltaics 3(1):407-415. http:// dx.doi.org/10.1109/JPHOTOV.2012.2217114.

Mills, Andrew D., and Ryan H. Wiser. 2012a. An Evaluation of Solar Valuation Methods Used in Utility Planning and Procurement Processes. LBNL-5933E. Berkeley, CA: Lawrence Berkeley National Laboratory. http://emp.lbl.gov/sites/all/files/lbnl-5933e 0.pdf.

- 2012b. Changes in the Economic Value of Variable Generation at High Penetration Levels: A Pilot Case Study of California. LBNL-5445E. Berkeley, CA: Lawrence Berkeley National Laboratory. http://emp.lbl.gov/sites/all/files/lbnl-5445e.pdf.

2015. "Strategies to mitigate declines in the economic value of wind and solar at high penetration in California." Applied Energy 147:269-278. http://dx.doi.org/10.1016/ j.apenergy.2015.03.014.

NERC (North American Electric Reliability Corporation). 2014. 2014 Long-Term Reliability Assessment. Atlanta: North American Electric Reliability Corporation. http://www.nerc.com/pa/ RAPA/ra/Reliability\%20Assessments\%20DL/2014LTRA_ERATTA.pdf.

Nourai, A., V.I. Kogan, and C.M. Schafer. 2008. "Load Leveling Reduces T\&D Line Losses." IEEE Transactions on Power Delivery 23(4): 2168-2173. http://dx.doi.org/10.1109/ TPWRD.2008.921128.

Olson, Arne, Nick Schlag, Kush Patel, and Gabe Kwok. 2014. Capital Cost Review of Power Generation Technologies: Recommendations for WECC's 10- and 20-Year Studies. Prepared by Energy and Environmental Economics, Inc. Salt Lake City: Western Electric Coordinating Council. https://www.wecc.biz/Reliability/2014 TEPPC Generation CapCost Report E3.pdf. 
Palchak, D., and P. Denholm. 2014. Impact of Generator Flexibility on Electric System Costs and Integration of Renewable Energy. NREL/TP-6A20-62275. Golden, CO: National Renewable Energy Laboratory. http://www.nrel.gov/docs/fy14osti/62275.pdf.

Perez, R., M. Taylor, T. Hoff, and J.P. Ross. 2008. "Reaching Consensus in the Definition of Photovoltaics Capacity Credit in the USA: A Practical Application of Satellite-Derived Solar Resource Data." IEEE Journal of Selected Topics in Applied Earth Observations and Remote Sensing 1(1):28-33. http://dx.doi.org/10.1109/JSTARS.2008.2004362.

Ricci, Bernardino, and Seok-Min Jung. 2015. "Energy storage levelized cost assessment: Lithium-ion vs. combustion turbine." 2015 IEEE 15th International Conference on Environment and Electrical Engineering (EEEIC) 357-362, June 10-13. http://dx.doi.org/10.1109/ EEEIC.2015.7165187.

Sioshansi, R., S.H. Madaeni, and P. Denholm. 2014. "A Dynamic Programming Approach to Estimate the Capacity Value of Energy Storage." IEEE Transactions on Power Systems 29(1):395-403. http://dx.doi.org/10.1109/TPWRS.2013.2279839.

Sioshansi, R.; Denholm, P.; Jenkin, T. (2012). "Market and Policy Barriers to Deployment of Energy Storage." Economics of Energy and Environmental Policy (1:2); pp. 47-63.

Sioshansi, R., P. Denholm, T. Jenkin, and J. Weiss. (2009) "Estimating the Value of Electricity Storage in PJM: Arbitrage and Some Welfare Effects" Energy Economics 31(2): 269-277.

Tuohy, A., and M. O’Malley. 2011. "Pumped Storage in Systems with Very High Wind Penetration." Energy Policy 39(4):1965-1974. http://dx.doi.org/10.1016/j.enpol.2011.01.026.

Ventyx. 2008. Analysis of "Loss of Load Probability" (LOLP) at various Planning Reserve Margins. Prepared for Public Service Company of Colorado. Denver: Public Service Company of Colorado.

Wärtsilä and Energy Exemplar. 2014. Incorporating Flexibility in Utility Resource Planning. Helsinki: Wärtsilä Corporation. http://energyexemplar.com/wp-content/uploads/publications/ 2014 EnergyExemplar/IOU\%20white\%20paper\%209.7.pdf.

WECC TEPPC (Western Electricity Coordinating Council Transmission Expansion Planning Policy Committee). 2011. TEPPC 2010 Study Program 10-Year Regional Transmission Plan. Salt Lake City: Western Electricity Coordinating Council. https://www.wecc.biz/Reliability/ 2011Plan_2020\%20Study\%20Report.pdf.

Xcel Energy Services, Inc. 2013. Effective Load Carrying Capability (ELCC) Study for Solar Generation Resources. Prepared for Public Service Company of Colorado. Denver: Public Service Company of Colorado.

Xi, X., and Sioshansi, R. (2014) A dynamic programming model of energy storage and transformer deployments to relieve distribution constraints. Computational Management Science. July 2014 http://dx.doi.org/10.1007/s10287-014-0218-6 


\section{Appendix A. Derivation of the Relationship between Battery Cost and CT Cost}

To perform this analysis, we set the annualized system costs for both cases (the CT case and the battery case) equivalent, and we solve for the battery capital cost. Annualized costs include all fixed and variable costs incurred by a utility. Because the vast majority of the costs are the same in both cases, we analyze only the annualized costs of the differences between the cases, primarily the difference in capital and operational costs.

The annualized fixed cost (AFC) of a CT is given by:

$$
A F C_{C T}=C R F_{C T} * C C_{C T}+F O M_{C T}
$$

where CC is capital cost, FOM is fixed O\&M, and $C R F$ is the Capital Recovery Factor, defined as:

$$
C R F=\frac{i(1+i)^{y}}{(1+i)^{y}-1}
$$

where $i$ is the interest rate and $y$ is number of annual payments, which we set to the system lifetime. We assume the life of a CT is 25 years.

The same calculation is applied to the battery, and setting total annualized costs for the CT case and battery case equal give us:

$$
\frac{i(1+i)^{y_{B A T}}}{(1+i)^{y_{B A T-1}}} * C C_{B A T}+F O M_{B A T}-V A L_{B A T}=\frac{i(1+i)^{y_{C T}}}{(1+i)^{y_{C T-1}}} * C C_{C T}+F O M_{C T}
$$

The annualized fixed cost term for the battery is the same is in eq. 1, but we have added the operational value difference between the case with the CT and the case with the battery $\left(V A L_{B A T}\right)$. This effectively reduces the annualized cost of the battery by its operational value compared to the CT case. In this analysis, we assume that the interest rate is the same for both technologies, implying in part equal "risk" on the part of a lender, so $i$ is identical. However, given the different lifetimes, we apply a different number of payment periods, so $y_{C T}=25$ and $y_{B A T}$ is parameterized.

Solving for $C C_{B A T}$ gives us:

$$
C C_{B A T}=\frac{\frac{i(1+i)^{y_{C T}}}{(1+i)^{y_{C T-1}}} * C C_{C T}+F O M_{C T}-F O M_{B A T}+V A L_{B A T}}{\frac{i(1+i)^{y_{B A T}}}{(1+i)^{y_{B A T-1}}}}
$$




\section{Appendix B. Generators in the Study}

Table B-1 lists the generators used for the 15\% PV base case. The 20\% PV case replaced 583.5 MW of coal capacity (LrmRStt3, Nucla2, and Nucla3) with four new CTs totaling $500 \mathrm{MW}$. The cases with the reduced reserve margin retired $553.5 \mathrm{MW}$ of coal capacity (LrmRStt 2). The names and values in the table are from the publicly available TEPPC data set.

Table B-1. Generators in the Study

\begin{tabular}{|c|c|c|c|c|c|}
\hline Name & Type & $\begin{array}{l}\text { Max. } \\
\text { Cap }\end{array}$ & Name & Type & $\begin{array}{l}\text { Max. } \\
\text { Cap }\end{array}$ \\
\hline FrntRang1 & CC Frame F & 510 & Pueblo Airport CT_1 & CT Future & 90 \\
\hline RckyMnt3 & CC Frame F & 621 & Pueblo Airport CT_2 & CT Future & 90 \\
\hline AmerAtlas1 & $\mathrm{CC}$ & 87 & Rawhide GT 5 & CT Future & 138 \\
\hline Arapaho7 & $\mathrm{CC}$ & 132 & SPNDLE1 & CT Future & 157 \\
\hline BrsCgn12 & $\mathrm{CC}$ & 120 & SPNDLE2 & CT Future & 157 \\
\hline BrsCgn3 & $\mathrm{CC}$ & 69.5 & BARRLAK1_1 & CT & 64 \\
\hline ColoPwPr2\#1 & $\mathrm{CC}$ & 75 & BARRLAK2_1 & CT & 64 \\
\hline FrtStVrainRP & $\mathrm{CC}$ & 758 & FrtStVrain5 & CT & 155 \\
\hline Greeley3 & $\mathrm{CC}$ & 75 & FrtStVrain6 & CT & 155 \\
\hline Pueblo Airport CC_1 & $\mathrm{CC}$ & 200 & Manchif1 & CT & 140 \\
\hline RMPP_Add_CC_2 & CC Future & 252 & Manchif2 & CT & 140 \\
\hline RMPP_Add_CC_3 & CC Future & 252 & AlamsGT1 & CT Gas & 17 \\
\hline ThrmFtL1 & $\mathrm{CC}$ & 181 & AlamsGT2 & CT Gas & 19 \\
\hline Thrmnd2B & $\mathrm{CC}$ & 33 & FrtLuptn1 & CT Gas & 50 \\
\hline Thrmnds 1 & $\mathrm{CC}$ & 116 & FrtLuptn2 & CT Gas & 50 \\
\hline Comanch1 & Coal & 331.8 & Fruita1 & CT Gas & 17 \\
\hline Comanch2 & Coal & 338 & LAMAR DC_1 & CT Gas & 210 \\
\hline Craig3 & Coal & 408 & RCDC W_1 & CT Gas & 200 \\
\hline Hayden2 & Coal & 286 & SIDNEYDC_1 & CT Gas & 200 \\
\hline LrmRStt2 & Coal & 553.5 & STEGALDC_1 & CT Gas & 100 \\
\hline LrmRStt3 & Coal & 553.5 & Valmont6 & CT Gas & 53 \\
\hline MartnDrk7 & Coal & 133.7 & $\begin{array}{l}\text { BenFrench CT1-CT4 } \\
\text { (4 units - } 25 \mathrm{MW} \text { each) }\end{array}$ & CT & 100 \\
\hline Pawnee1 & Coal & 498.2 & $\begin{array}{l}\text { FntnVly 1-6 (6 units - } \\
40 \mathrm{MW} \text { each) }\end{array}$ & CT & 240 \\
\hline Rawhide1 & Coal & 288 & Lange 1 & CT & 38.7 \\
\hline RayDNxn1 & Coal & 205 & NSimpGT1 & CT & 38.7 \\
\hline WYGEN 3 & Coal & 100 & NSimpGT2 & CT & 40 \\
\hline Nucla2 & Coal & 15 & PlnsEnd1 & CT & 55 \\
\hline
\end{tabular}




\begin{tabular}{|c|c|c|c|c|c|}
\hline Name & Type & $\begin{array}{l}\text { Max. } \\
\text { Cap }\end{array}$ & Name & Type & $\begin{array}{l}\text { Max. } \\
\text { Cap }\end{array}$ \\
\hline Nucla3 & Coal & 15 & PInsEnd2 & CT & 55 \\
\hline LamrPIt1 & Coal & 38 & RawhdGT4 & CT & 63 \\
\hline MartnDrk5 & Coal & 47 & RDNixonG1 & CT & 40 \\
\hline NSimpsN1 & Coal & 18.6 & RDNixonG2 & CT & 40 \\
\hline NSimpsN2 & Coal & 82.2 & BnFrnchD1 & IC & 10 \\
\hline Nucla4 & Coal & 70 & BnFrnchD2 & IC & 10 \\
\hline Valmont7 & Coal & 37 & Interconnection Export & & 32.214 \\
\hline Valmont8 & Coal & 37 & CabinCreek_1 & Pumped Storage & 162 \\
\hline WYGEN & Coal & 82.2 & CabinCreek_2 & Pumped Storage & 162 \\
\hline WYGEN 2 Wyodak & Coal & 100 & ELBERT-1_1 & Pumped Storage & 100 \\
\hline Comanche III & Coal SuperC & 750 & ELBERT-2_1 & Pumped Storage & 100 \\
\hline CO State Rollup & Hydro & 23.25 & NCWCD_1 & Pumped Storage & 36 \\
\hline CO State Rollup (2) & Hydro & 69.75 & BBILL1-2_1 & Hydro_Fixed & 9 \\
\hline Shoshone & Hydro & 14.4 & BBILL3-4_1 & Hydro_Fixed & 9 \\
\hline TESLA1_1 & Hydro & 27.6 & FONTNLLE_1 & Hydro_Fixed & 10 \\
\hline WY State Rollup & Hydro & 22 & AptDiesl & Steam & 10 \\
\hline ALCOVA1_1 & Hydro_Fixed & 20 & GeorgBrds1 & Steam & 23 \\
\hline ALCOVA2_1 & Hydro_Fixed & 20 & GeorgBrds2 & Steam & 17 \\
\hline BMESA1-2_1 & Hydro_Fixed & 43.2 & GeorgBrds3 & Steam & 17 \\
\hline BMESA1-2_2 & Hydro_Fixed & 43.2 & Pueblo 6 & Steam & 20 \\
\hline BOYSEN1_1 & Hydro_Fixed & 15 & RockyFrd & Steam & 10 \\
\hline CRYSTAL_1 & Hydro_Fixed & 27.5 & PublDs|1 & Steam & 10 \\
\hline $\begin{array}{l}\text { ESTES ( } 3 \text { units at } 15 \\
\text { MW each) }\end{array}$ & Hydro_Fixed & 45 & Cherokee RP CC & CC Repower & 350 \\
\hline FLATIRN1_2 & Hydro_Fixed & 43 & Cherokee4 RP & CC Repower & 624 \\
\hline FLATIRN2_1 & Hydro_Fixed & 43 & Cherokee RP CT1 & CT Repower & 100 \\
\hline $\begin{array}{l}\text { FLGORG ( } 3 \text { units at } \\
50 \text { MW each) }\end{array}$ & Hydro_Fixed & 150 & Cherokee RP CT2 & CT Repower & 100 \\
\hline FREMONT1_1 & Hydro_Fixed & 33.4 & MORRO1-2_1 & Hydro_Fixed & 80 \\
\hline FREMONT2_1 & Hydro_Fixed & 33.4 & MORRO1-2_2 & Hydro_Fixed & 80 \\
\hline $\begin{array}{l}\text { GLENDO ( } 2 \text { units at } \\
19 \text { MW each) }\end{array}$ & Hydro_Fixed & 38 & $\begin{array}{l}\text { YELLO (4 units }-72 \\
\text { MW each) }\end{array}$ & Hydro_Fixed & 288 \\
\hline $\begin{array}{l}\text { GREENMT ( } 2 \text { units } \\
\text { at } 13 \mathrm{MW} \text { each) }\end{array}$ & Hydro_Fixed & 26 & $\begin{array}{l}\text { KORTES ( } 3 \text { units at } 12 \\
\text { MW each) }\end{array}$ & Hydro_Fixed & 36 \\
\hline $\begin{array}{l}\text { PLNENDG (14 units } \\
-8.257 \text { MW each) }\end{array}$ & IC & 116 & $\begin{array}{l}\text { SEMINOE ( } 3 \text { units at } \\
15 \mathrm{MW} \text { each) }\end{array}$ & Hydro_Fixed & 15 \\
\hline
\end{tabular}

